IZA DP No. 8806

Bargaining and Wage Rigidity in a Matching Model for the US

James M. Malcomson

Sophocles Mavroeidis

January 2015 


\title{
Bargaining and Wage Rigidity in a Matching Model for the US
}

\author{
James M. Malcomson \\ University of Oxford \\ and IZA \\ Sophocles Mavroeidis \\ University of Oxford
}
Discussion Paper No. 8806
January 2015

IZA
P.O. Box 7240
53072 Bonn
Germany

Phone: +49-228-3894-0

Fax: +49-228-3894-180

E-mail: iza@iza.org

\begin{abstract}
Any opinions expressed here are those of the author(s) and not those of IZA. Research published in this series may include views on policy, but the institute itself takes no institutional policy positions. The IZA research network is committed to the IZA Guiding Principles of Research Integrity.

The Institute for the Study of Labor (IZA) in Bonn is a local and virtual international research center and a place of communication between science, politics and business. IZA is an independent nonprofit organization supported by Deutsche Post Foundation. The center is associated with the University of Bonn and offers a stimulating research environment through its international network, workshops and conferences, data service, project support, research visits and doctoral program. IZA engages in (i) original and internationally competitive research in all fields of labor economics, (ii) development of policy concepts, and (iii) dissemination of research results and concepts to the interested public.
\end{abstract}

IZA Discussion Papers often represent preliminary work and are circulated to encourage discussion. Citation of such a paper should account for its provisional character. A revised version may be available directly from the author. 


\section{ABSTRACT}

\section{Bargaining and Wage Rigidity in a Matching Model for the US $^{*}$}

The Mortensen and Pissarides (1994) matching model with all wages negotiated each period is shown inconsistent with macroeconomic wage dynamics in the US. This applies even when heterogeneous match productivities, time to build vacancies and credible bargaining are incorporated. Wage rigidity consistent with micro evidence that wages of job changers are more flexible than those of job stayers allows the model to capture these dynamics and is not inconsistent with parameter calibrations in the literature. Such wage rigidity affects only the timing of wage payments over the duration of matches, so conclusions about characteristics based on calibrations continue to apply.

JEL Classification: E2, J3, J6

Keywords: matching frictions, wage bargaining, wage rigidity

Corresponding author:

James M. Malcomson

University of Oxford

All Souls College

Oxford OX1 4AL

United Kingdom

E-mail: james.malcomson@economics.ox.ac.uk

\footnotetext{
We thank participants in seminars at IZA/CEPR European Summer Symposium in Labour Economics, at LSE and at Oxford for very helpful comments. Malcomson thanks Leverhulme Trust Major Research Fellowship F/08519/B for financial support of this research. Mavroeidis thanks the European Commission for financial support of this research under a FP7 Marie Curie Fellowship CIG 293675.
} 


\section{Introduction}

This paper studies wage equations for the US in the matching model of Mortensen and Pissarides (1994), the leading approach in recent discussions of unemployment and vacancies at the macroeconomic level. It makes two main contributions. First, it shows that none of the formulations in the literature with wages in all matches negotiated each period satisfies the natural criterion of adequately capturing the macroeconomic dynamics of wages. Second, it provides a formulation of wage rigidity that does so and, consistent with the micro evidence reported in Pissarides (2009) and reiterated by Haefke et al. (2013), applies only to continuing matches, with wages negotiated for all new matches.

These results are important for the following reason. If wage rigidity applies to new, as well as continuing, matches, as in Gertler and Trigari (2009), it affects job creation and hence vacancies and unemployment. But, as pointed out by Malcomson (1999, Section 4) and Pissarides (2009), if it applies only to continuing matches, it affects only the timing of wage payments over the duration of a match. So conclusions for vacancies and unemployment drawn from studies without wage rigidity continue to apply.

Many empirical implementations of the Mortensen and Pissarides (1994) model assume Nash bargaining of wages in all matches each period. See, for example, Cole and Rogerson (1999), Yashiv (2000), Shimer (2005), Yashiv (2006) and Hagedorn and Manovskii (2008). Hagedorn and Manovskii (2008) argue explicitly that their formulation satisfactorily reflects US data. Others are more sceptical and incorporate history dependence in view of the considerable evidence from individual panel data of wage rigidity at the microeconomic level. ${ }^{1}$ Studies include Shimer (2004), Hall (2005a), Hall (2005b), Hall and Milgrom (2008), Gertler and Trigari (2009), Rudanko (2009), Rudanko (2011) and Kudlyak (2014). ${ }^{2}$ Gertler and Trigari (2009) show that, with the addition of wage rigidity, the matching model can account for the cyclical behaviour of both wages and labour market activity. But the form of wage rigidity they use assumes wages for new matches are just as rigid as wages for continuing matches, an assumption criticised by Pissarides (2009). From his survey of the microeconometric evidence, Pissarides (2009) concludes that wages of job changers (new matches) are substantially more procyclical than those of job stayers (continuing matches). He also argues that, provided account is taken of fixed costs incurred after matching has occurred, a model with just wages for new matches determined by the standard Nash bargain can account for the observed volatility of unemployment. He does not, however, develop a specific model of wage rigidity for continuing matches that actually captures the macroeconomic dynamics of wages.

The underlying problem for capturing the macrodynamics of wages with models in which

\footnotetext{
${ }^{1}$ See Dickens et al. (2007) for an overview of results from the International Wage Flexibility Project.

${ }^{2}$ There is also a growing literature applying disaggregated versions of the matching model with heterogeneous firms and employees to micro data. For examples, see Cahuc et al. (2006) and Robin (2011).
} 


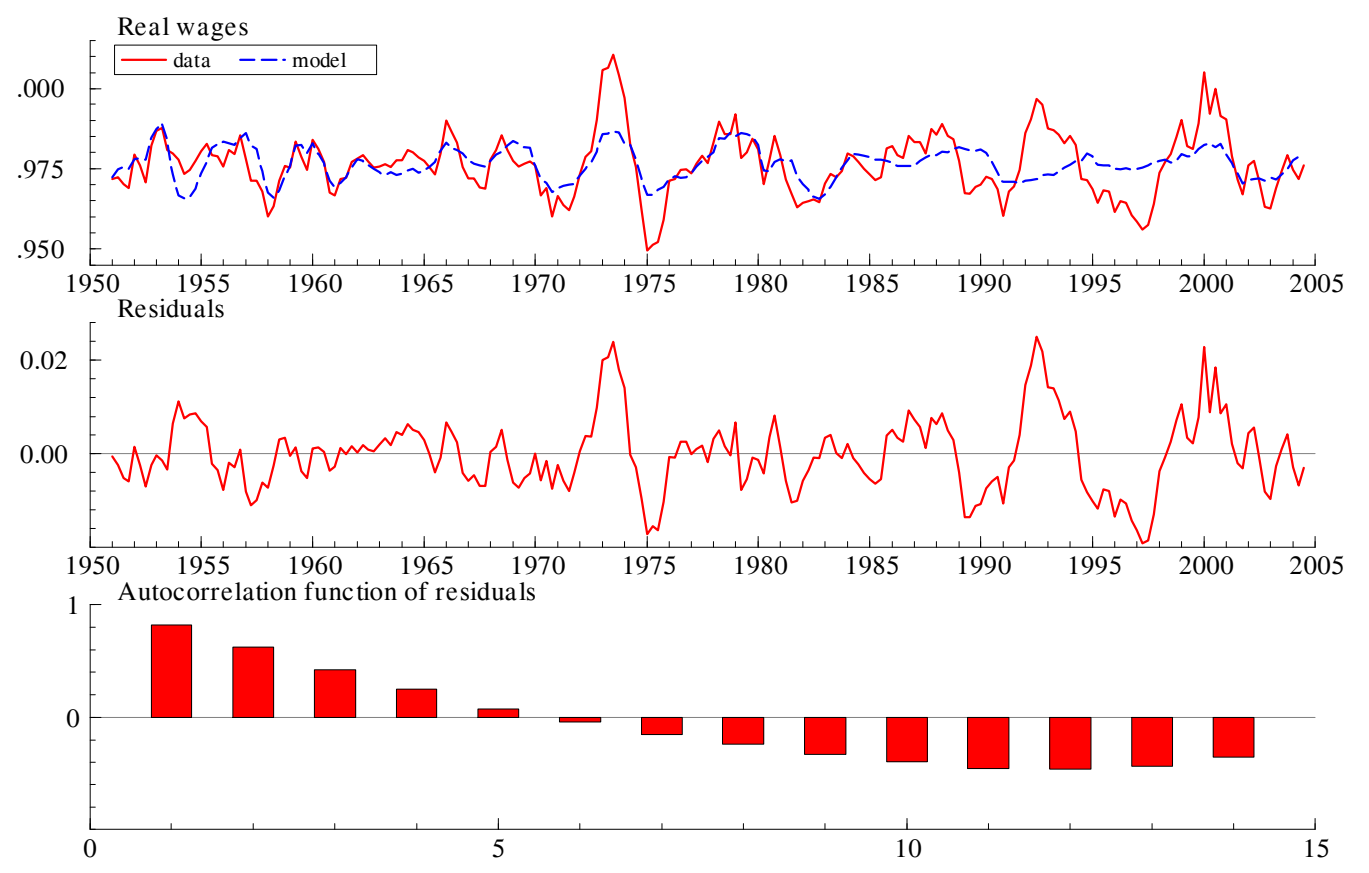

Figure 1: Top panel: real wages and corresponding fitted values for the calibration in Hagedorn and Manovskii (2008). Middle panel: residuals $=$ differences between data and model. Bottom panel: autocorrelation function of residuals. Data: Hagedorn and Manovskii (2008).

wages in all matches are determined by the Nash bargain in every period is illustrated in Figure 1. This compares the variation in the wage predicted by the calibration in Hagedorn and Manovskii (2008) with the average wage in the data. The residuals are the difference between these. It is apparent from the figure that the residuals are highly persistent (as measured by the autocorrelation function), which is contrary to what one would expect if the model captured adequately the dynamics of wages in the data.

Subsequent contributions have extended the model with all wages negotiated each period to address this problem. Hall and Milgrom (2008) consider a different model of bargaining, credible bargaining. Hagedorn and Manovskii (2011) allow for "time to build" in vacancy creation. Hagedorn and Manovskii (2013) add heterogeneity to match productivities and allow "on the job" search by workers. To these can be added the fixed costs (for training, negotiation or administration) incurred after matching suggested by Pissarides (2009). In this paper, we construct an empirically implementable model that encompasses all these when all wages are negotiated each period and show that, even with them all combined, the model still does not satisfactorily capture the macroeconomic dynamics of wages in the US.

As an alternative to all wages being negotiated in each period, this paper constructs an empirically implementable model with wage rigidity for continuing matches but wages negotiated afresh 
for all new matches. The form of wage rigidity is that developed in Gertler and Trigari (2009) but applied only to continuing, not to new, matches. This formulation satisfactorily captures the macroeconomic dynamics of wages in the US, despite having essentially only one additional parameter. Alternative forms of wage rigidity for continuing matches are developed by Thomas and Worrall (1988), Beaudry and DiNardo (1991), Rudanko (2009) and MacLeod and Malcomson (1993). The first three, however, depend on workers being risk averse, which is not part the standard matching model, and MacLeod and Malcomson (1993) is harder to implement empirically with aggregate data. In any case, the purpose here is not to select between different models of wage rigidity for continuing matches but to show that a wage equation with these general characteristics can capture the macroeconomic dynamics of wages. The model we use is an empirically tractable one that suffices for this purpose.

Our empirical analysis is based on limited-information estimation using the generalized method of moments (GMM). Limited-information analysis is appealing because it allows us to avoid making assumptions about the stochastic processes underlying a model that are not integral to it and thus potentially rejecting the model because those auxiliary assumptions are inappropriate. The models we estimate are forward-looking rational expectations models and this characteristic provides straightforward criteria for determining valid instruments. Moreover, in drawing our conclusions we make use of methods of inference that are robust to weak instruments, see Stock and Wright (2000), and thus reduce the risk of drawing inappropriate inferences from statistical tests.

The paper is organized as follows. The next section sets out the theoretical wage equations we use for econometric analysis. That is followed by sections on empirical specifications, the data and estimation results. These are, in turn, followed by a conclusion. Appendix A sets out the full details of the theoretical model from which the wage equations are derived. Appendix B contains further derivations of equations in Appendix A, Appendix C a formal model of "on the job" search, Appendix D additional information about the data used, and Appendix E supplementary empirical results and robustness checks.

\section{Theoretical wage equations}

\subsection{Wage equations without wage rigidity}

The basic framework used here is the matching model of Mortensen and Pissarides (1994) as developed by Hagedorn and Manovskii (2008) for empirical analysis. The model consists of five equations: (1) a value equation for a filled job, (2) a value equation for an unfilled vacancy that is set to zero because free entry is assumed, (3) a value equation for an employed worker, (4) a value equation for an unemployed worker, and (5) a Nash bargaining equation that determines wages. 


\begin{tabular}{|c|l|}
\hline Notation & Description \\
$p_{t}$ & average productivity in matches at $t$ \\
$w_{t}$ & average wage in matches at $t$ \\
$\delta_{t}$ & discount factor applied to $t+1$ at $t$ \\
$s_{t}$ & match separation probability at $t$ \\
$c_{t}$ & vacancy posting cost at $t$ \\
$\gamma_{t}$ & difference in cost to firm and worker of making offers at $t$ with credible bargaining \\
$q_{t}$ & probability of filling a vacancy at $t$ \\
$f_{t}$ & probability of an unemployed worker finding employment at $t$ \\
$z_{t}$ & value of non-work activity at $t$ \\
$\lambda$ & Nash bargain: $\beta /(1-\beta)$, for $\beta$ the bargaining power of a worker \\
& credible bargain: probability of negotiation breakdown \\
$\kappa$ & probability that employment starts at $t$ for new match at $t$ \\
$\delta_{t}^{\kappa}$ & $\delta_{t-1}\left(1-s_{t}-f_{t-1}+\kappa s_{t} f_{t-1}\right)$ \\
\hline
\end{tabular}

Table 1: Notation for all wages bargained each period

We adapt those equations to encompass the credible bargaining model of Hall and Milgrom (2008) as an alternative to the Nash bargaining model, "time to build" in vacancy creation as suggested in Hagedorn and Manovskii (2011), heterogeneity in match productivities as suggested in Hagedorn and Manovskii (2013) and fixed costs incurred only after matching as suggested by Pissarides (2009), together with some minor generalizations of inessential restrictions that there is no reason to require the data to satisfy. The full model is set out in Appendix A. There we derive a wage equation that, when wages in all matches are negotiated each period and with the notation in Table 1 , takes the form

$$
w_{t}=\frac{z_{t}}{1+\lambda}+\frac{\lambda}{1+\lambda}\left[p_{t}+c_{t} \frac{f_{t}}{\left(1-f_{t} \kappa\right) q_{t}}\right]+\frac{\lambda}{1-\lambda^{2}} \frac{\gamma_{t}-E_{t}\left(\delta_{t+1}^{\kappa} \gamma_{t+1}\right)}{1-f_{t} \kappa} .
$$

This reduces to exactly the wage equation in Hagedorn and Manovskii (2008) when the parameters incorporating the extensions to the model are set to appropriate values; specifically, $\kappa=0$ (employment starts at $t+1$ for new matches at $t$ ) and $\gamma_{t}=0$ for all $t$ (no cost to making offers so bargaining is Nash). Given appropriate specifications for $z_{t}, c_{t}$ and $\gamma_{t},(1)$ is an equation for the average wage that can be estimated from available data.

To interpret (1), start with Nash bargaining $\left(\gamma_{t}=0\right.$ for all $\left.t\right)$. If employment lasted only a single period, the worker would receive payoff $z_{t}$ and the firm 0 (because, at the bargaining stage, $c_{t}$ is a sunk cost) if they do not form a match at $t$. If they form a match, the parties have productivity $p_{t}$ to share between them. So Nash bargaining would result in $w_{t}=z_{t}+\beta\left(p_{t}-z_{t}\right)$, where $\beta \in[0,1]$ is the bargaining power of the worker. (To encompass the credible bargaining model, $\beta$ is replaced by $\lambda /(1+\lambda)$ in (1).) With a continuing match, there is also the future to consider. With Nash bargaining at $t+1$ as well as at $t$, the worker's expected future gains are proportional to the firm's 
expected future gains. Moreover, because of free entry, the firm's expected gains from $t+1$ on equal the cost $c_{t}$ of posting a vacancy at $t$ less the period $t$ gains. So, all future payoffs can be written explicitly in terms of variables known at $t$, including $c_{t}$ as in (1). See Appendix A for the detailed derivation. The term in (1) including $\gamma_{t}$ and $\gamma_{t+1}$ needs to be added to incorporate credible bargaining. For that model, $\lambda$ has a different interpretation, see Table 1 , but it still affects the other terms in the same way as with Nash bargaining.

Equation (1) also captures the model of "on the job" search in Hagedorn and Manovskii (2013), see Appendix A. But that model does not take explicit account of the change in the distribution of match productivities over the business cycle induced by selection as workers search on the job for more productive matches. In Appendix A, we present a wage equation that takes explicit account of this. It includes variables we cannot calculate from the data, so we are not able to provide direct estimates. However, as argued more technically in Appendix A, the effect of on the job search works in the wrong direction for reconciling bargaining of wages for all matches in every period with the persistence of wages in the data.

In the model in the appendix, on the job search introduces history dependence because free entry now equates the average of the expected payoffs to the firm of filling a vacancy at $t$ with an unemployed and an employed worker to $c_{t}$. The probability of filling the vacancy with an employed worker depends on the distribution of productivities at $t-1$ because employed workers switch only to a job with higher productivity. In deriving the equivalent of equation (1) for this model, one must subtract that history dependent term from $c_{t}$. So, when the distribution of actual productivities at $t-1$ is untypically favourable to high productivities (and, because of Nash bargaining, also high wages at $t-1)$, the average wage at $t$ is untypically low. Therefore, the effect on wage dynamics is in the opposite direction of what is needed to generate the persistence in the data.

For reasons explained above, wage equation (1) depends on the future gains from the relationship being satisfactorily measured in terms of the cost $c_{t}$ of creating a vacancy at $t$. It therefore depends on the value equation for an unfilled vacancy being properly specified. If it is not, (1) is mis-specified even if wages in all matches are negotiated every period. In particular, there are some specifications of the time to build a vacancy in Hagedorn and Manovskii (2011) that affect the value of an unfilled vacancy but are not captured in the specification used to derive (1). Thus, our subsequent finding that (1) does not fit the data could result purely from this mis-specification, not because some wages are not negotiated every period.

To rule out this possibility, we derive in Appendix A an alternative wage equation when all wages are bargained each period that, although making use of the free entry condition that the value of creating a vacancy is zero, does not rely on the specification of the equation for that value. 
This wage equation has the form

$$
\begin{aligned}
\left(1-f_{t} \kappa\right)\left(w_{t}-z_{t}\right)-\lambda\left(p_{t}-w_{t}\right) & \\
+E_{t} \sum_{n=1}^{\infty}\left[\delta_{t, n}^{\kappa}-\delta_{t} \delta_{t+1, n-1}^{\kappa}\left(1-s_{t+1}\right)\right]\left(1-f_{t+n} \kappa\right)\left(w_{t+n}-z_{t+n}\right) & -\frac{\lambda}{1-\lambda}\left[\gamma_{t}-\delta_{t} E_{t}\left(1-s_{t+1}\right) \gamma_{t+1}\right]=0
\end{aligned}
$$

where $\delta_{t, n}^{\kappa}=\prod_{i=1}^{n} \delta_{t+i}^{\kappa}$, with $\delta_{t, 0}^{\kappa}=1$, and $\delta_{t}^{\kappa}=\delta_{t-1}\left(1-s_{t}-f_{t-1}+\kappa s_{t} f_{t-1}\right)$. Instead of capitalising a worker's future gains from forming a match in terms of the cost $c_{t}$ of creating a vacancy, wage equation (2) spells out those future gains explicitly in the terms $w_{t+n}-z_{t+n}$ for $n \geq 1$. It is thus robust to the specification of the equation for the value of creating a vacancy and, in particular, remains valid for any length of time to build a vacancy. It thus encompasses all the specifications in Hagedorn and Manovskii (2011). Estimation of (2) requires the terms under the summation sign to be truncated at some finite horizon. ${ }^{3}$ With $\delta_{t}^{\kappa}$ strictly less than 1 as implied by the model, however, the approximation error from truncation can be made arbitrarily small for a sufficiently long horizon. Given appropriate specifications for $z_{t}$ and $\gamma_{t},(2)$ is then an equation in current and future average wages that can be estimated from available data.

\subsection{Wage equation with wage rigidity}

Gertler and Trigari (2009) use a form of wage rigidity that enables the matching model to account for the cyclical behaviour of wages and labour market activity. Their form of wage rigidity has a fixed probability that the wage for a match, whether new or continuing, is bargained in any one period. But Haefke et al. (2013) find little evidence of wage rigidity for new hires at the microeconomic level, reinforcing the micro evidence surveyed by Pissarides (2009). Here, therefore, we use a model in which wages in continuing matches are subject to wage rigidity of the type analysed by Gertler and Trigari (2009) but those in new matches are all bargained.

In Appendix A, we derive a wage equation for the average wage in new matches, $w_{t}^{*}$, when the wage for continuing matches is renegotiated with probability $1-\psi$. We allow for the possibility that wages not renegotiated may be adjusted automatically to inflation by scaling them by the factor $\pi_{t}^{-\mu}$, where $\pi_{t}$ is the ratio of prices at $t$ to prices at $t-1$ and $\mu$ is a parameter to be estimated. Wages here are measured in real terms. Thus, for $\mu=1$, the unrenegotiated wage is set in nominal terms, for $\mu=0$ in real terms, with $\mu \in(0,1)$ interpreted as the proportion of unrenegotiated

\footnotetext{
${ }^{3}$ This approach has been used by, for example, Rudd and Whelan (2006) for studying the new Keynesian Phillips curve.
} 
wages set in nominal terms. The wage equation then takes the form

$$
\begin{aligned}
&\left(1-f_{t} \kappa\right)\left(w_{t}^{*}-z_{t}\right)-\lambda\left[\left(1-f_{t} \kappa\right)\left(p_{t}-w_{t}^{*}\right)+c_{t} \frac{f_{t}}{q_{t}}\right] \\
&-\frac{\lambda}{1-\lambda}\left[\gamma_{t}-E_{t}\left(\delta_{t+1}^{\kappa} \gamma_{t+1}\right)\right]+\psi(1+\lambda) E_{t}\left\{\delta _ { t + 1 } ^ { \kappa } \left(\pi_{t+1}^{-\mu} w_{t}^{*}\right.\right. \\
&\left.\left.-w_{t+1}^{*}\right)\left[\sum_{i=1}^{\infty} \prod_{j=2}^{i}\left(\delta_{t+j-1}\left(1-s_{t+j}\right) \psi \pi_{t+j}^{-\mu}\right)\right]\right\}=0,
\end{aligned}
$$

where, as before, $\delta_{t}^{\kappa}=\delta_{t-1}\left(1-s_{t}-f_{t-1}+\kappa s_{t} f_{t-1}\right)$. When $\psi=0, w_{t}^{*}=w_{t}$ and wage equation (3) reduces to (1). In (1), with Nash bargaining only contemporaneous variables appear. (With credible bargaining, the costs of making offers at $t+1$ also appear.) Wage rigidity gives rise to forward-looking behaviour because the wage currently negotiated may continue to apply at future dates, which is captured by $\psi \neq 0$. Thus, our specification of wage rigidity involves relaxing the single restriction $\psi=0$, which turns out to make a big difference empirically.

The data contain the average wage $w_{t}$ but not the average wage for new matches $w_{t}^{*}$. Appendix A shows that, under the assumptions of the model, the relationship between these is given by

$$
w_{t}^{*}=\frac{w_{t}-\pi_{t}^{-\mu} w_{t-1}}{1-\psi\left(1-s_{t}\right) j_{t-1} / j_{t}}+\pi_{t}^{-\mu} w_{t-1} .
$$

As with (2), estimation of (3) requires the terms under the summation sign on the right-hand side to be truncated at some finite horizon. With $\delta_{t+j-1}\left(1-s_{t+j}\right) \psi$ strictly less than 1 , the approximation error from truncation can be made arbitrarily small for a sufficiently long horizon.

\section{Empirical specifications}

Empirical implementation of (1)-(3) requires specifications for $z_{t}, \gamma_{t}$ and $c_{t}$. In Hagedorn and Manovskii (2008), productivity is detrended and $z_{t}$ is a constant. The corresponding assumption here is that $z_{t}$ is proportional to trend productivity, denoted $\bar{p}_{t}$. We make the same assumption for $\gamma_{t}$. These give the specifications

$$
z_{t}=z \bar{p}_{t}, \quad \gamma_{t}=\gamma \bar{p}_{t}, \quad \text { where } z \geq 0 \text {. }
$$

For the vacancy posting cost, Hagedorn and Manovskii (2008) include two components, capital and labour. Capital costs in period $t$ are proportional to productivity in period $t$ and so can be written $c^{K} p_{t}$, where $c^{K}$ is a non-negative constant. ${ }^{4}$ Labour costs in period $t$ are proportional

\footnotetext{
${ }^{4}$ Hagedorn and Manovskii (2008) actually assume that capital costs are $c^{K} p_{t} / \bar{p}$ and normalize $\bar{p}$ to one, but then HP filter the data, so this is equivalent to assuming that, after detrending the cost by the productivity trend, it is
} 
to the cyclical component of productivity, $\tilde{p}_{t}=p_{t} / \bar{p}_{t}$, raised to the power $\xi \in[0,1]$, which Hagedorn and Manovskii (2008) interpret as the elasticity of the labour cost of those engaged in hiring with respect to productivity, and so can be written $c^{W} \tilde{p}_{t}^{\xi} \bar{p}_{t}$, where $c^{W}$ is a non-negative constant. See Hagedorn and Manovskii (2008) for a detailed discussion of the motivation for these formulations. We add to these the post-matching fixed costs suggested in Pissarides (2009), denoted by $H_{t}$, which we allow to have both capital and labour components specified in ways corresponding to the vacancy posting costs in Hagedorn and Manovskii (2008), so

$$
H_{t}=H^{K} p_{t}+H^{W} \tilde{p}_{t}^{\xi} \bar{p}_{t}, \quad H^{K}, H^{W} \geq 0
$$

Because these costs are incurred only in the event of a match, they are multiplied by the probability of matching $q_{t}$ in their impact on vacancy creation. Combining all these components for $c_{t}$, we get the empirical specification

$$
c_{t}=c^{K} p_{t}+c^{W} \tilde{p}_{t}^{\xi} \bar{p}_{t}+\left(H^{K} p_{t}+H^{W} \tilde{p}_{t}^{\xi} \bar{p}_{t}\right) q_{t}, \quad c^{K}, c^{W}, H^{K}, H^{W} \geq 0, \xi \in[0,1] .
$$

For estimation, we normalize the wage equations (1), (2) and (3) by trend productivity, which corresponds to the use of detrended productivity in Hagedorn and Manovskii (2008) and ensures all variables are stationary. ${ }^{5}$

\section{Data}

We use data on the nonfarm business sector of the USA, mainly from the Bureau of Labor Statistics (BLS) and the OECD. The data are quarterly and cover the period 1951q1 to 2011q4. Our baseline estimation results are for the period up to $2004 q 4$ for comparability with earlier studies. A fuller description of the data is in Appendix D.

We use this data to construct model-consistent data series. The number of new matches at $t$, $m_{t}$, is given by the total number of filled jobs at $t, j_{t}$, less the number of continuing matches at $t$, $\left(1-s_{t}\right) j_{t-1}$, so

$$
m_{t}=j_{t}-\left(1-s_{t}\right) j_{t-1} .
$$

The stock of vacancies at the end of period $t$, after matching takes place, is denoted $v_{t}$. Hence, the total number of vacancies available to be filled in period $t$ is $v_{t}+m_{t}$. The stock of unemployed workers seeking matches in period $t$ consists of workers who were unemployed in the previous period, $l_{t-1}-j_{t-1}$ (where $l_{t}$ is the labour force at $t$ ), workers who were employed in the previous proportional to the business cycle variation in productivity.

${ }^{5}$ We measure trend productivity using the HP filter with parameter 1600, as in Hagedorn and Manovskii (2008). We detrend wages and productivity by the same productivity trend. The results are robust to the alternative of HP filtering each series separately, see Table 13 in Appendix E. 
period but have lost their job, $s_{t} j_{t-1}$, and net new entrants to the labour force, $\Delta l_{t}=l_{t}-l_{t-1}$, making $l_{t}-\left(1-s_{t}\right) j_{t-1}$ in total. Equivalently, this is given by the stock of unemployed workers at the end of the period, $u_{t}$, plus the total matches during the period, $u_{t}+m_{t}$. Thus, the probability of filling a vacancy in period $t$ is given by

$$
q_{t}=\frac{m_{t}}{v_{t}+m_{t}}
$$

and the job-finding probability for unemployed workers by

$$
f_{t}=\frac{m_{t}}{u_{t}+m_{t}}
$$

Employment $j_{t}$ and unemployment $u_{t}$ are constructed and seasonally adjusted by the BLS from the CPS. They correspond to the last month in the quarter in accordance with the model used here. Employment consists of total nonfarm dependent employment (excluding the self-employed). The labour force is the sum of employed and unemployed.

We adopt the practice discussed by Blanchard and Diamond (1990) of constructing a series for separations from the number of short-term unemployed, $u_{t}^{s}$, in our case (because we are using quarterly data) those with spells shorter than 14 weeks. Moreover, if the increase in the labour force all goes through the unemployment pool first, this increase should be subtracted from the shortterm unemployed before calculating the separation rate. We adjusted the data for this, though the effect on the calculated series for the separation rate $s_{t}$ is very small. We also adjusted for direct job-to-job flows using the procedure suggested in Shimer (2005) based on the idea that, on average, a worker losing a job has half a period to find a new one before being recorded as unemployed. Thus, short-term unemployment satisfies

$$
u_{t}^{s}=\left(1-\frac{1}{2} f_{t}\right)\left(\Delta l_{t}+s_{t} j_{t-1}\right) .
$$

Use of (7) and (9) to express $f_{t}$ as $\left[j_{t}-\left(1-s_{t}\right) j_{t-1}\right] /\left[l_{t}-\left(1-s_{t}\right) j_{t-1}\right]$ enables us to solve for a series for $s_{t}$ that is consistent with the model. ${ }^{6}$ The resulting series is plotted in Figure 2. This series is higher than the monthly separation rate series reported elsewhere (e.g., Shimer (2005, Figure 7)), but it matches the cyclical pattern of the (monthly) series exactly. It illustrates the point made by Mortensen and Nagypál (2007) and by Shimer (2005) that separation rates have not been constant over this period.

Vacancy stocks $v_{t}$ are measured using the Conference Board Help-Wanted Index (HWI), which is available in quarterly frequency from 1951 to $2008 .^{7}$ The index is converted to total units using

\footnotetext{
${ }^{6}$ Even with the adjustment suggested by Shimer (2005), the measure of separations does not include workers moving directly from jobs to self-employment or to leaving the labour force but it is not clear how to allow for that.

${ }^{7}$ The HWI series based on printed newspaper advertising was replaced by online advertising after 2008. The two
} 


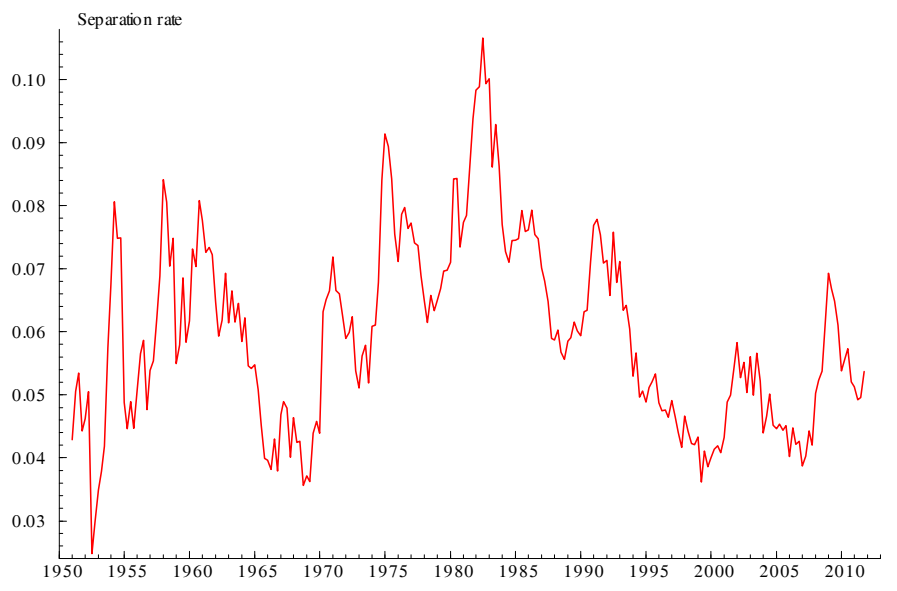

Figure 2: The separation rate $s_{t}$ computed from $u_{t}^{s}=\left(1-\frac{1}{2} \frac{j_{t}-\left(1-s_{t}\right) j_{t-1}}{l_{t}-\left(1-s_{t}\right) j_{t-1}}\right)\left(\Delta l_{t}+s_{t} l_{t-1}\right)$ using employment, unemployment and short-term unemployment data from the BLS.

the job-openings series from the Job Openings and Labor Turnover Survey (JOLTS), which is available only since December 2000. The HWI is known to contain low frequency fluctuations, such as those resulting from newspaper consolidation in the 1960s and the internet revolution recently, that are unrelated to labour market trends, see Shimer (2005). Following Shimer (2005), we remove the effect of those trends using a low frequency filter, see Appendix D for details. The probability of filling a vacancy $q_{t}$ is then calculated using data on employment and vacancies via equations (7) and (8). The resulting series is plotted in Figure 3. We also plot on the same graph the corresponding series for $v_{t}$ derived using the JOLTS data over the period (2001 on) for which it is available. This shows that the two series match very closely (their correlation is 0.9 ).

Wages and productivity are from the BLS, which provides a measure of the labour share (including non-wage compensation) and output per person in the nonfarm business sector. We adjust for the ratio of marginal to average productivity using the scaling factor 0.679 computed by Hagedorn and Manovskii (2008). Because we use quarterly data, we specify the discount factor as $\delta_{t}=\frac{1}{1+r_{t} / 4}$, where $r_{t}$ is the annualized gross real interest rate, which we measure as the quarterly average of daily 3-month Treasury bill interest rates deflated using the implicit price deflator for nonfarm business obtained from the BLS.

series have coexisted since 2005. Barnichon (2010) compiled a composite print and online HWI index that extends to 2011. For comparability with Shimer (2005) and Hagedorn and Manovskii (2008), we use the original HWI series. Robustness checks to alternative vacancy series are reported in Appendix E. 


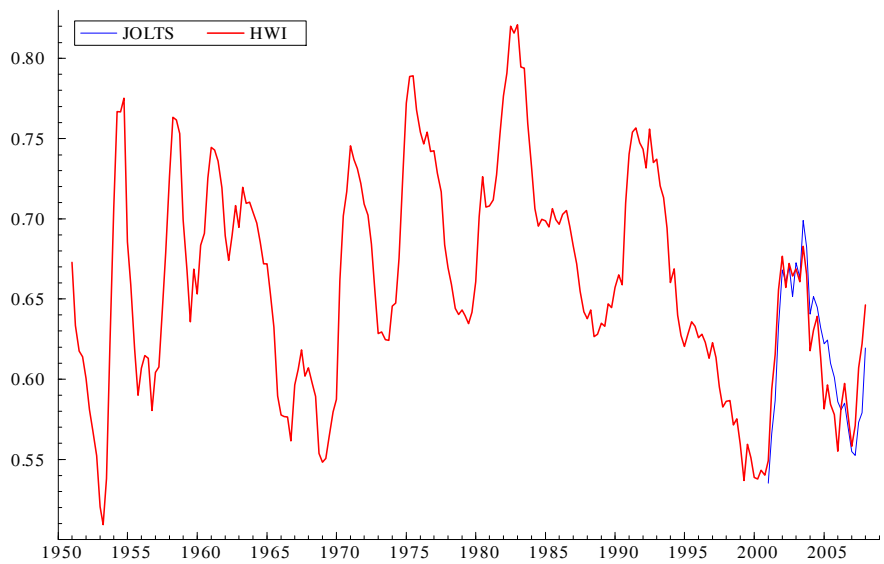

Figure 3: The vacancy-filling probability $q_{t}$ using employment data from the BLS and vacancy data from the Conference Board HWI and from JOLTS.

\section{Estimation results}

Estimation of equations (1), (2) and (3) is performed with GMM (Hansen (1982)). For robustness to weak identification, we use the continuously updated estimator (CUE) proposed by Hansen et al. (1996), and the S test proposed by Stock and Wright (2000). Confidence sets based on the S test can be empty if the identifying restrictions are rejected for all admissible values of the parameters. To check whether this is the case, it suffices to compare the minimum value of the $\mathrm{S}$ test statistic to its critical value. This coincides with the $J$ statistic of Hansen (1982) that tests the validity of over-identifying restrictions, but unlike the standard Hansen test, the use of a higher critical value makes it robust to weak identification. ${ }^{8}$

Let $\phi_{t}(\theta)$ denote the expression on the left-hand side of (1), (2) or (3), as appropriate, with the expectations operator removed, where $\theta$ is the vector of model parameters. This is a parametric function of observed variables, whose expectation conditional on variables known at $t$ is zero if expectations are rational. The model's testable implications can then be expressed in terms of orthogonality restrictions of the form $E\left[Z_{t} \phi_{t}(\theta)\right]=0$, where $Z_{t}$ is a vector of instruments at $t$. Rational expectations imply that lagged values of variables are uncorrelated with current and future error terms so, as standard in macroeconomic time-series models with rational expectations, we use lags of the variables in the model as instruments. Given the quarterly frequency of the sample, we use four lags. ${ }^{9}$ For the estimation, parameter values are constrained to be consistent with the model, specifically $z, \kappa, \psi, \mu, \xi \in[0,1]$, and $\lambda, c^{K}, c^{W}, H^{K}, H^{W} \geq 0$.

\footnotetext{
${ }^{8}$ See, for example, Mavroeidis et al. (2014, Section A.2.6).

${ }^{9}$ Because results may become unreliable when the number of instruments is large, see Andrews and Stock (2007), we avoid using a larger number of instruments, but we find that our results are robust to different sets of instruments, see Appendix E.
} 
All calculations were performed using Ox, see Doornik (2007).

\subsection{Results with wages bargained in all matches every period}

We first present estimates for the model with wages bargained in all matches each period. Table 2 reports results for wage equation (1).

Column 1 of Table 2 reports estimates for the specification in Hagedorn and Manovskii (2008) with $\kappa$, the fraction of newly matched jobs that become active in less than one period, and the cost parameters $H^{K}$ and $H^{W}$ set to 0 . (The parameters $\gamma$ and $\lambda$ do not appear in this specification.) A "period" in Hagedorn and Manovskii (2008) is one week. Here each period is a quarter, so this specification corresponds to a longer lag between the decision to create a vacancy and the possibility of the job becoming productive, as suggested by Hagedorn and Manovskii (2011). (A shorter lag corresponds to $\kappa>0$, which we allow for in column 2.) The point estimate of $z$, the value of non-work activity, is essentially identical to the calibrated value 0.936 in Hagedorn and Manovskii (2011) for the corresponding productivity series and the other parameters have large standard errors - reassuring evidence that, when applied to the same formulation, our estimation procedure yields results not inconsistent with their calibration procedure. But the over-identifying restrictions of this model (implied by errors uncorrelated with the lagged instruments we use) are overwhelmingly rejected by the Hansen test, even that using the more conservative projection $p$ value that is robust to weak identification. Column 2 reports estimates with $\kappa$ restricted only to $[0,1]$. The point estimate of $\kappa$ is zero and the value of the GMM objective function indicates that this generalization of the timing does not improve fit. Column 3 of Table 2 reports estimates allowing for the fixed costs $H^{K}$ and $H^{W}$ in the spirit of Pissarides (2009). This generalization does not significantly improve the fit of the model either. For both these extensions, the Hansen test continues to overwhelmingly reject the over-identifying restrictions. The standard errors are large, especially so for the cost parameters. But these standard errors are unreliable for constructing confidence intervals because there is no guarantee that the assumptions underlying standard $t$ tests are satisfied.

An alternative to Nash bargaining is the credible bargaining of Hall and Milgrom (2008). Equation (1) with $\gamma$ unrestricted and $\lambda \in[0,1)$ corresponds to our formulation of credible bargaining for application to quarterly data. Column 4 of Table 2 reports estimates for this model. Allowing $\gamma$ to be non-zero makes little difference to the fit, as measured by the value of the GMM objective function. It also leaves the over-identifying restrictions rejected just as overwhelmingly by the Hansen test.

Rejection by the Hansen test does not provide information about which aspects of the model fail to fit the data. One way to assess this informally is by regressing the residuals of the model on 


\begin{tabular}{|c|c|c|c|c|}
\hline Parameter & 1 & 2 & 3 & 4 \\
\hline$\beta$ & $\begin{array}{l}0.036 \\
(0.891)\end{array}$ & $\begin{array}{l}0.036 \\
(0.843)\end{array}$ & $\begin{array}{l}0.033 \\
(2.568)\end{array}$ & $\frac{-}{(-)}$ \\
\hline$z$ & $\begin{array}{l}0.937 \\
(0.060)\end{array}$ & $\begin{array}{l}0.937 \\
(0.056)\end{array}$ & $\begin{array}{l}0.887 \\
(0.308)\end{array}$ & $\begin{array}{l}0.880 \\
(0.411)\end{array}$ \\
\hline$c^{K}$ & $\begin{array}{l}0.440 \\
(1803)\end{array}$ & $\begin{array}{c}0.440 \\
(953)\end{array}$ & $\begin{array}{c}0.006 \\
(751)\end{array}$ & $\frac{0.201}{(579)}$ \\
\hline$c^{W}$ & $\begin{array}{l}0.267 \\
(1817)\end{array}$ & $\begin{array}{c}0.270 \\
(966)\end{array}$ & $\begin{array}{c}0.399 \\
(777)\end{array}$ & $\frac{0.254}{(627)}$ \\
\hline$\xi$ & $\begin{array}{l}0.382 \\
(4292)\end{array}$ & $\begin{array}{l}0.383 \\
(2290)\end{array}$ & $\begin{array}{c}0.006 \\
(1891)\end{array}$ & $\begin{array}{l}0.000 \\
(2388)\end{array}$ \\
\hline$\kappa$ & $\frac{-}{(-)}$ & $\begin{array}{l}0.000 \\
(0.390)\end{array}$ & $\begin{array}{l}0.069 \\
(0.382)\end{array}$ & $\begin{array}{l}0.046 \\
(0.425)\end{array}$ \\
\hline$H^{K}$ & $\frac{-}{(-)}$ & $\frac{-}{(-)}$ & $\begin{array}{c}2.279 \\
(245)\end{array}$ & $\begin{array}{l}1.753 \\
(1100)\end{array}$ \\
\hline$H^{W}$ & $\frac{-}{(-)}$ & $\frac{-}{(-)}$ & $\begin{array}{c}0.157 \\
(243)\end{array}$ & $\begin{array}{l}0.599 \\
(1313)\end{array}$ \\
\hline$\gamma$ & $\frac{-}{(-)}$ & $\frac{-}{(-)}$ & $\frac{-}{(-)}$ & $\begin{array}{c}0.716 \\
(86.3)\end{array}$ \\
\hline$\lambda$ & $\overline{(-)}$ & $\frac{-}{(-)}$ & $\overline{(-)}$ & $\begin{array}{l}0.031 \\
(3.632)\end{array}$ \\
\hline GMM objective & 34.459 & 34.457 & 33.395 & 33.315 \\
\hline Hansen test $p$ value & 0.001 & 0.001 & 0.000 & 0.000 \\
\hline Hansen test proj. $p$ value & 0.007 & 0.007 & 0.010 & 0.010 \\
\hline
\end{tabular}

Table 2: Estimates of models without wage rigidity, eq. (1).

Notes: In all models, $z$ is the value of non-work activity, $c^{K}, c^{W}$ are capital and labour vacancy posting costs, $\xi$ is the elasticity of the labour cost of those engaged in hiring with respect to productivity, $\kappa$ is the fraction of matched jobs that become active within the quarter, and $H^{K}, H^{W}$ are Pissarides (2009) fixed costs. For the Nash bargaining model (columns 1-3), $\beta$ is the workers' bargaining weight. For the credible bargaining model (column 4 ), $\gamma$ is the difference betwen firms' and workers' costs of making offers, and $\lambda$ is the probability negotiations do not break down between offers. Estimation method is CUE-GMM with Newey-West weight matrix with prewhitening over the sample $1952 \mathrm{q} 2-2004 \mathrm{q} 4$, with a constant and four lags of $w_{t}, p_{t}, f_{t}$ and $q_{t}$ as instruments. Standard errors in parentheses. The Hansen test $p$ value is computed from a $\chi^{2}(N-v)$ distribution where $N$ is the number of instruments and $v$ is the number of parameters estimated in the interior of the parameter space. The Hansen test proj. $p$ value is derived from a $\chi^{2}(N)$ distribution. 


\begin{tabular}{|c|c|c|}
\hline Parameter & 1 & 2 \\
\hline$\beta$ & $\begin{array}{l}0.111 \\
(0.030)\end{array}$ & - \\
\hline$z$ & $\begin{array}{l}0.865 \\
(0.018)\end{array}$ & $\begin{array}{l}0.933 \\
(0.019)\end{array}$ \\
\hline$\kappa$ & $\begin{array}{l}0.000 \\
(0.356)\end{array}$ & $\begin{array}{l}1.000 \\
(0.242)\end{array}$ \\
\hline$\gamma$ & $\begin{array}{l}0.000 \\
(0.000)\end{array}$ & $\begin{array}{c}-0.926 \\
(0.219)\end{array}$ \\
\hline$\lambda$ & - & $\begin{array}{l}0.092 \\
(0.023) \\
\end{array}$ \\
\hline GMM objective & 37.899 & 36.486 \\
\hline Hansen test $p$ value & 0.001 & 0.001 \\
\hline Hansen test proj. $p$ value & 0.003 & 0.004 \\
\hline
\end{tabular}

Table 3: Estimates of models without wage rigidity independent of the value of creating a vacancy, eq. (2), with the infinite sum truncated at 13 quarters.

Notes: In both models, $z$ is the value of non-work activity and $\kappa$ is the fraction of matched jobs that become active within the quarter. For the Nash bargaining model (column 1), $\beta$ is the workers' bargaining weight. For the credible bargaining model (column 2), $\gamma$ is the difference betwen firms' and workers' costs of making offers, and $\lambda$ is the probability negotiations do not break down between offers. Estimation method is CUE-GMM with Newey-West weight matrix with prewhitening over the sample 1952q2-2004q4, with a constant and four lags of $w_{t}, p_{t}, f_{t}$ and $q_{t}$ as instruments. Standard errors in parentheses. The Hansen test $p$ value is computed from a $\chi^{2}(N-v)$ distribution where $N$ is the number of instruments and $v$ is the number of parameters estimated in the interior of the parameter space. The Hansen test proj. $p$ value is derived from a $\chi^{2}(N)$ distribution.

the instruments. This reveals that the instrument that drives the rejection is $w_{t-1}$ : its coefficient is close to one, while the coefficients on all other instruments are very close to zero. This supports the message from Figure 1 that it is the persistence of wages that the model fails to capture.

Wage equation (1) is derived making use of the equation for the value of a vacancy. Rejection of (1) might, therefore, be the result of misspecification of that equation and not a rejection of wage bargaining for every job in every period. We check for this by estimating wage equation (2), which is derived without any assumption about the form of the equation for the value of a vacancy. It is consistent with any length of time to build a vacancy of the type considered in Hagedorn and Manovskii (2011). Table 3 reports the results of estimating that.

For the results in Table 3, the infinite sum in (2) is truncated at 13 quarters, which makes use of all the data available for the variables in that sum while keeping the estimation sample the same as in Table 2, for comparability with Hagedorn and Manovskii (2008). The point estimates are, however, very insensitive to the truncation length. Column 1 gives results for Nash bargaining, column 2 for credible bargaining. Because wage equation (2) does not include $c_{t}$, it does not yield estimates of the cost parameters. But the important point here is that, despite these specifications not depending on the form of the equation for the value of a vacancy, both Nash and credible bargaining formulations continue to be resoundingly rejected. The implication is that no alternative specification of the value of creating a vacancy will enable either bargaining model with wages for 
all jobs bargained in every period to capture the dynamics of wages in the data.

The most important point from these results is that, for all the specifications with wages negotiated in all matches in every period, the Hansen tests resoundingly reject the over-identifying restrictions with a $p$ value of $1 \%$ or lower even using the most conservative critical values robust to weak identification, implying that the instruments are correlated with the residuals. Another implication is that the confidence intervals discussed above that are robust to weak identification are completely empty even at the $99 \%$ level for every parameter, despite the large standard errors. There just does not exist any set of economically feasible parameter values that enable these models to capture in a statistically satisfactory way the dynamic pattern of wages in the data. Because the formulation allows for heterogeneous match productivity and on the job search as in Hagedorn and Manovskii (2013), this is strong evidence that these extensions of the basic matching model, either alone or together, are insufficient to enable the model with the wage for each job bargained in every period to capture the pattern of wages in the data. Moreover, the results in Table 3 imply that no alternative formulation of the value of creating a vacancy, whether to incorporate time to build as in Hagedorn and Manovskii (2011) or anything else, can overcome this.

The implication is that something more is required to enable the model to fit the dynamics of wages. It need not be wage rigidity. But in the next section we show that the addition of wage rigidity of the form modelled in Section 2.2 does enable the model to do so.

\subsection{Results with wage rigidity}

Wage equation (3) can be used to test the Nash and credible bargaining specifications in the presence of wage rigidity of the form in Section 2.2. The results of estimating that specification, with $w_{t}^{*}$ specified by (4) and the infinite sum truncated at 28 quarters, are reported in columns 1-5 of Table 4. (Truncation at 28 quarters makes use of all the data available up to the end of 2011 for the variables in the infinite sum while leaving the estimation sample at 1952q2-2004q4 as used by Hagedorn and Manovskii (2008). Table 12 in Appendix E gives results for other truncation lengths. Beyond 8 quarters, the point estimates are completely insensitive to the truncation length.) The results in columns 1-4 are directly comparable to the corresponding columns of Table 2 . The most important finding is that, unlike the specifications without wage rigidity, these specifications all comfortably pass the Hansen tests of over-identifying restrictions at conventional levels of significance. Addition of the single extra parameter $\psi$ is the reason for this. Thus for the model with wage rigidity, unlike for that without wage rigidity, there exist sets of parameter values that satisfactorily capture wage dynamics in US data.

The cost parameters $c^{K}, c^{W}, \xi, H^{K}$ and $H^{W}$ are not precisely estimated from the aggregate time-series data we use for columns 1-4 of Table 4 . (This is shown formally by the confidence in- 


\begin{tabular}{c|ccccc}
\hline \hline Parameter & 1 & 2 & 3 & 4 & 5 \\
\hline$\psi$ & 0.743 & 0.606 & 0.606 & 0.631 & 0.742 \\
$\mu$ & $(0.027)$ & $(0.069)$ & $(0.073)$ & $(0.084)$ & $(0.026)$ \\
$\beta$ & 0.123 & 0.023 & 0.023 & 0.000 & 0.130 \\
& $(0.228)$ & $(0.314)$ & $(0.366)$ & $(0.454)$ & $(0.218)$ \\
$z$ & 0.090 & 0.077 & 0.077 & - & 0.060 \\
$c^{K}$ & $(3.303)$ & $(2.230)$ & $(5.154)$ & $(-)$ & $(0.045)$ \\
& 0.946 & 0.943 & 0.943 & 1.000 & 0.947 \\
$c^{W}$ & $(0.198)$ & $(0.137)$ & $(0.340)$ & $(0.125)$ & $(0.013)$ \\
$\xi$ & 0.001 & 0.007 & 0.007 & 0.000 & 0.194 \\
$\kappa$ & $(1931.862)$ & $(606.350)$ & $(876.154)$ & $(121.400)$ & $(-)$ \\
& 0.149 & 0.046 & 0.046 & 0.083 & 0.045 \\
$H^{K}$ & $(1935.586)$ & $(607.306)$ & $(879.118)$ & $(130.336)$ & $(-)$ \\
& 0.293 & 0.085 & 0.085 & 0.000 & 0.449 \\
$H^{W}$ & $(9394.965)$ & $(12360.664)$ & $(17529.835)$ & $(1169.534)$ & $(-)$ \\
& - & 1.000 & 1.000 & 1.000 & 0.000 \\
$\gamma$ & $(-)$ & $(0.334)$ & $(0.359)$ & $(0.395)$ & $(-)$ \\
& - & - & 0.000 & 0.011 & 0.000 \\
$\lambda$ & $(-)$ & $(-)$ & $(101.850)$ & $(1200.852)$ & $(-)$ \\
& - & - & 0.000 & 1.145 & 0.000 \\
& $(-)$ & $(-)$ & $(102.460)$ & $(1317.720)$ & $(-)$ \\
& - & - & - & -1.376 & 0.000 \\
Hansen test $p$ value & $(-)$ & $(-)$ & $(-)$ & $(176.249)$ & $(-)$ \\
\hline Hansen test proj. $p$ value & 0.390 & 0.399 & 0.399 & 0.629 & 0.643 \\
\hline \hline
\end{tabular}

Table 4: Estimates of models with wage rigidity, eq. (3), with $w_{t}^{*}$ specified by (4) and the infinite sum truncated at 28 quarters.

Notes: In all models, $\psi$ is the proportion of wages not negotiated in a quarter, $\mu$ is the proportion of wages not negotiated that are set in nominal terms, $z$ is the value of non-work activity, $c^{K}, c^{W}$ are capital and labour vacancy posting costs, $\xi$ is the elasticity of the labour cost of those engaged in hiring with respect to productivity, $\kappa$ is the fraction of matched jobs that become active within the quarter, and $H^{K}, H^{W}$ are Pissarides (2009) fixed costs. For the Nash bargaining model (columns 1-3 and 5), $\beta$ is the workers' bargaining weight. For the credible bargaining model (column 4), $\gamma$ is the difference between firms' and workers' costs of making offers, and $\lambda$ is the probability negotiations do not break down between offers. In column 5, the cost parameters are calibrated using the approach of Hagedorn and Manovskii (2008). Estimation method is CUE-GMM with Newey-West weight matrix with prewhitening over the sample 1952q2-2004q4, with a constant and four lags of $w_{t}, p_{t}, f_{t}$ and $q_{t}$ as instruments. Standard errors in parentheses. The Hansen test $p$ value is computed from a $\chi^{2}(N-v)$ distribution where $N$ is the number of instruments and $v$ is the number of parameters estimated in the interior of the parameter space. The Hansen test proj. $p$ value is derived from a $\chi^{2}(N)$ distribution. 


\begin{tabular}{c|cccc}
\hline \hline Parameter & & Nash Barg. & Cred. Barg. & Nash Barg. calibr. \\
\hline$\psi$ & $95 \%$ & {$[0.15,0.90]$} & {$[0.25,0.90]$} & {$[0.62,0.90]$} \\
& $90 \%$ & {$[0.21,0.88]$} & {$[0.25,0.88]$} & {$[0.64,0.87]$} \\
$\beta$ & $95 \%$ & {$[0.00,0.94]$} & - & {$[0.00,0.24]$} \\
& $90 \%$ & {$[0.00,0.84]$} & - & {$[0.00,0.22]$} \\
$z$ & $95 \%$ & {$[0.25,1.00]$} & {$[0.11,1.00]$} & {$[0.88,0.97]$} \\
$\lambda$ & $90 \%$ & {$[0.65,1.00]$} & {$[0.20,1.00]$} & {$[0.89,0.97]$} \\
& $95 \%$ & - & {$[0.00,0.999]$} & \\
& $90 \%$ & - & {$[0.00,0.999]$} & \\
\hline \hline
\end{tabular}

Table 5: Confidence intervals based on the $S$ test of Stock and Wright (2000) for the specifications in columns 3, 4 and 5 of Table 4.

Notes: Confidence intervals reported only for parameters for which they do not comprise the entire admissible parameter range. In the first two columns all the remaining parameters are unrestricted. In the column "Nash Barg. calibr.", $\mu=0$ and the rest of the parameters are fixed at the calibrated values given in column 5 of Table 4 .

tervals robust to weak identification that we report below). Calibration studies typically use other data to determine values of cost parameters. In column 5, we report estimates of $\beta$ and $z$ for the Nash bargaining model (together with the wage rigidity parameters) when the cost parameters are calibrated following the procedure in Hagedorn and Manovskii (2008). Fixing the cost parameters in this way hardly affects the fit of the model (compare with column 3, the unrestricted specification) and this specification still comfortably passes the Hansen tests. Thus wage rigidity allows the model to capture the dynamics of wages with values of the cost parameters consistent with those commonly used in calibrated versions of the matching model.

Because standard errors are unreliable for constructing confidence intervals in the present context, we construct confidence intervals that are robust to weak identification using the $S$ test of Stock and Wright (2000) in order to see how large the set of statistically acceptable parameter values is. Unlike in the models in which wages are bargained for every match in every period, confidence intervals for standard significance levels constructed in this way are not empty. Confidence intervals at the $95 \%$ and $90 \%$ level for the specifications that correspond to columns 3 and 4 in Table 4 are reported in the first two columns of Table 5, respectively. (The final column of Table 5 is discussed below). Confidence intervals for parameters not reported in Table 5 comprise the entire parameter space; they are completely uninformative. In the case of the cost parameters $c^{K}, c^{W}, \xi, H^{K}, H^{W}$, and $\gamma$, this is explained by the fact that they are unidentified when $\lambda=0$ because then these parameters drop out of equation (3) and the restriction $\lambda=0$ (which also corresponds to $\beta=0$ ) is acceptable at the $10 \%$ level in both specifications.

It may help with interpreting the confidence intervals in Table 5 to explain how they are constructed. Consider the confidence interval for the parameter $\psi$ (the parameter that determines the degree of wage rigidity). For each value of $\psi$, say $\psi_{0}$, in the range of economically feasible values 
(in this case $[0,1]$ ), we check whether there are any values of the remaining parameters such that the model's identifying restrictions are statistically acceptable at the desired level of significance. Specifically, we compare the value of the S statistic, minimized over all parameters subject to the restriction $\psi=\psi_{0}$, to the appropriate $95 \%$ or $90 \%$ quantile of the $\chi^{2}$ distribution with degrees of freedom equal to the number of identifying restrictions. The confidence interval contains all the values $\psi_{0}$ for which this test accepts. This procedure is repeated over a grid of values from 0 to 1 , with increment .01 (so the confidence intervals are correct to two decimal places). Thus, the top row of confidence intervals for $\psi$ in Table 5 shows that there is no set of values for the parameters other than $\psi$ that enables the Nash bargaining specification to pass the $S$ test at the appropriate significance level for a value of $\psi$ less than 0.15 or greater than 0.90 . But there is a set that does so for each intermediate value of $\psi$. For this parameter, all the confidence intervals exclude zero, confirming the results of the previous section that, without wage rigidity, the model is statistically unacceptable. They also exclude one, that is, completely rigid wages in continuing matches. However, the confidence intervals for $\mu$ cover the entire parameter space, indicating that this parameter is not identified, so the data is not sufficiently informative to distinguish between nominal and real wage rigidity.

For $z$, the value of non-work activity as a proportion of productivity, the confidence intervals in the first two columns of Table 5 are sufficiently wide to contain the values reported in earlier studies that used calibration. In the Nash bargaining specification, the confidence intervals for $\beta$ are also wide, including values from zero to more than 0.8 . The corresponding parameter $\lambda$ in the credible bargaining specification has the confidence intervals that contain all the values from 0 to 0.999 that we searched over. (For $\lambda=1$, the model is not defined.) In particular, they contain the calibrated value 0.995 in Hall and Milgrom (2008). There is thus very considerable latitude to choose parameter values based on other data sources used to calibrate matching models that will enable the model to capture the dynamics of wages if allowance is made for wage rigidity.

The column "Nash Barg calibr." reports confidence intervals for $\psi, \beta$ and $z$ in the Nash bargaining specification with wage rigidity when $\mu=0$ (real wage rigidity) and all other parameters are fixed at the calibrated values in column 5 of Table 4 . The confidence intervals for these parameters are very much smaller than in the other columns, so the use of additional sources of information to calibrate the cost parameters substantially reduces the uncertainty surrounding the point estimates. These confidence intervals have $\beta$ below 0.25 , and the value of non-market activity $z$ no lower than 0.88, and neither inconsistent with their values in Hagedorn and Manovskii (2008) and Hagedorn and Manovskii (2011). Such values of non-market activity are, however, higher than Mortensen and Nagypál (2007) and Hall and Milgrom (2008) regard as plausible (Hall and Milgrom (2008) suggest a calibrated value of 0.71 ), so this remains an important puzzle that cannot be addressed just by allowing for wage rigidity of the form used here. 
The key message from these results is that there is a form of wage rigidity that enables the model to capture in a statistically satisfactory way the dynamics of wages in US data. The time series data we use are not themselves sufficiently informative to tie down the parameters of the model tightly. But there is plenty of scope for determining parameter values from other data sources that will capture those dynamics when wage rigidity is included in the model. That is in contrast to the model with wages for all matches bargained every period, for which the time series data are sufficiently informative to rule out any set of economically feasible parameter values that does this. These conclusions remain robust to several variations in the data and specification, see Appendix E.

\subsection{Implications of the results}

One implication of our results is that matching models with fully flexible wages of the type Hagedorn and Manovskii argue in a series of papers captures the behaviour of vacancies and unemployment do not capture the macroeconomic dynamics of wages. The alternative proposed by Gertler and Trigari (2009) with the same degree of wage rigidity in all matches has been criticised by Pissarides (2009) as inconsistent with the micro evidence that wages of job changers (new matches) are substantially more flexible than those of job stayers (continuing matches). A second implication of our results is that a wage equation consistent with this micro evidence, with wage rigidity only in continuing matches and flexible wages for all new matches, can capture the macroeconomic dynamics of wages.

This second implication is important. As Malcomson (1999, Section 4) and Pissarides (2009) point out, wage rigidity that applies only to continuing matches, unlike wage rigidity that applies to all matches as in Gertler and Trigari (2009), has implications for unemployment and vacancies no different from fully flexible wages, provided it does not result in inefficient separations. Wage negotiation for new matches takes account of the wage rigidity and sets an initial wage such that the expected present value of wages over the duration of the match is unaffected by that wage rigidity. The wage rigidity thus results merely in an intertemporal redistribution of that expected present value and so has no effect on the incentives for vacancy creation. Inefficient separations do not occur in the model used here because all separations are assumed to be for exogenous reasons, though even with endogenous separations they can be avoided by renegotiation. There is thus no need to use wage equations that have implications for unemployment and vacancies different from fully flexible wages to capture the macroeconomic dynamics of wages.

Other messages that come across strongly from our results are the following. The credible bargaining model of Hall and Milgrom (2008) with all wage negotiated each period fares no better than Nash bargaining in capturing the dynamics of wages. With our formulation of wage rigidity 
that applies only to continuing matches, with the wage negotiated for all new matches, the lower bound of the $95 \%$ confidence interval for the proportion of wages not negotiated each quarter is comfortably above zero, and this conclusion is robust to weak identification. The time-series data we use are, however, not sufficiently informative to enable us to identify whether the rigidity should be modelled in nominal or in real wages.

Moreover, among the sets of parameter values that capture those dynamics, there is plenty of scope for selecting a set that is consistent with the other empirical evidence typically used for calibration of matching models. In particular, those sets include the calibrated values in Hagedorn and Manovskii (2008), Hall and Milgrom (2008), Pissarides (2009), Hagedorn and Manovskii (2011) and many other papers in the literature. Thus our results are not inconsistent with the findings of other studies concerning those parameters, as long as allowance is made for wage rigidity in continuing matches. Disagreements between those studies about appropriate values for the parameters need to be settled by other evidence.

\section{Conclusion}

In this paper, we have investigated econometrically wage equations for a matching model of the US. We makes two main contributions. First, we show that none of the formulations in the literature with wages in all matches negotiated each period satisfies the natural criterion of adequately capturing the macroeconomic dynamics of wages. Second, we provide a formulation of wage rigidity that does so and, consistent with the micro evidence reported in Pissarides (2009) and Haefke et al. (2013), applies only to continuing matches, with wages negotiated for all new matches.

We reach this conclusion by nesting the Nash bargaining model and the credible bargaining model of Hall and Milgrom (2008) within a common over-arching framework of which each is a special case. The framework allows for heterogeneous match productivities and "on the job" search as modelled in Hagedorn and Manovskii (2013) and gives rise to a wage equation that can be estimated in a way that allows for the time to build in vacancy creation in Hagedorn and Manovskii (2011) of any length. It enables us to apply standard statistical tests to investigate which models are statistically acceptable restrictions of the over-arching framework and, in particular, capture the dynamics of wages. Our statistically acceptable specification includes a parameter that allows for wage rigidity in continuing, but not new, matches. Only with this parameter strictly positive can the model capture the macroeconomic dynamics of wages. But this form of wage rigidity has implications for unemployment and vacancies no different from fully flexible wages. There is no need to use a wage equation with wage rigidity for new matches, with its markedly different implications for unemployment and vacancies, to capture the macroeconomic dynamics of wages. 


\section{References}

Andrews, D. W. and Stock, J. H. (2007), 'Testing with many weak instruments', Journal of Econometrics 127(1), 24-46.

Barnichon, R. (2010), 'Building a composite Help-Wanted Index’, Economics Letters 109(3), 175178.

Beaudry, P. and DiNardo, J. (1991), 'The effect of implicit contracts on the movement of wages over the business cycle: Evidence from micro data', Journal of Political Economy 99(4), 665688.

Becker, G. S. (1975), Human Capital: A Theoretical and Empirical Analysis, with Special Reference to Education, 2nd edn, Columbia University Press, New York.

Billingsley, P. (1995), Probability and measure, Wiley.

Blanchard, O. J. and Diamond, P. (1989), 'The Beveridge curve', Brookings Papers on Economic Activity 1, 1-60.

Blanchard, O. J. and Diamond, P. (1990), 'The cyclical behavior of the gross flows of U.S. workers', Brookings Papers on Economic Activity (2), 85-143.

Cahuc, P., Postel-Vinay, F. and Robin, J.-M. (2006), 'Wage bargaining with on-the-job search: Theory and evidence', Econometrica 74(2), 323-364.

Chéron, A. and Langot, F. (2004), 'Labor market search and real business cycles: Reconciling nash bargaining with the real wage dynamics', Review of Economic Dynamics 7(2), 476-493.

Cole, H. L. and Rogerson, R. (1999), 'Can the Mortensen-Pissarides matching model match the business-cycle facts?', International Economic Review 40(4), 933-959.

Diamond, P. A. (1982), 'Aggregate demand management in search equilibrium', Journal of Political Economy $90(5), 881-894$.

Dickens, W. T., Goette, L., Groshen, E. L., Holden, S., Messina, J., Schweitzer, M. E., Turunen, J. and Ward, M. E. (2007), 'How wages change: Micro evidence from the International Wage Flexibility Project', Journal of Economic Perspectives 21(2), 195-214.

Doornik, J. A. (2007), Object-Oriented Matrix Programming Using Ox, 3rd edn, Timberlake Consultants Press, London. 
Gertler, M. and Trigari, A. (2009), 'Unemployment fluctuations with staggered Nash wage bargaining', Journal of Political Economy 117(1), 38-86.

Haefke, C., Sonntag, M. and van Rens, T. (2013), 'Wage rigidity and job creation', Journal of Monetary Economics 60(8), 887-899.

Hagedorn, M. and Manovskii, I. (2008), 'The cyclical behavior of equilibrium unemployment and vacancies revisited', American Economic Review 98(4), 1692-1706.

Hagedorn, M. and Manovskii, I. (2011), 'Productivity and the labor market: Comovement over the business cycle', International Economic Review 52(3), 603-619.

Hagedorn, M. and Manovskii, I. (2013), 'Job selection and wages over the business cycle', American Economic Review 103(2), 771-803.

Hall, R. E. (2005a), 'Employment efficiency and sticky wages: Evidence from flows in the labor market', Review of Economics and Statistics 87(3), 397-407.

Hall, R. E. (2005b), 'Employment fluctuations with equilibrium wage stickiness', American Economic Review 95(1), 50-65.

Hall, R. E. and Milgrom, P. R. (2008), 'The limited influence of unemployment on the wage bargain', American Economic Review 98(4), 1653-1674.

Hansen, L. P. (1982), 'Large sample properties of generalized method of moments estimators', Econometrica 50(4), 1029-54.

Hansen, L. P., Heaton, J. and Yaron, A. (1996), 'Finite sample properties of some alternative GMM estimators', Journal of Business and Economic Statistics 14, 262-280.

Kudlyak, M. (2014), 'The cyclicality of the user cost of labor', Journal of Monetary Economics 68, 53-67.

MacLeod, W. B. and Malcomson, J. M. (1993), 'Investments, holdup, and the form of market contracts', American Economic Review 83(4), 811-837.

MacLeod, W. B. and Malcomson, J. M. (1998), 'Motivation and markets', American Economic Review 88(3), 388-411.

Malcomson, J. M. (1999), Individual employment contracts, in O. Ashenfelter and D. Card, eds, 'Handbook of Labor Economics', Vol. 3B, Elsevier, Amsterdam, chapter 35, pp. 2291-2372. 
Mavroeidis, S., M. Plagborg-Møller and J. H. Stock (2014), 'Empirical evidence on inflation expectations in the New Keynesian Phillips curve', Journal of Economic Literature 52(1), 124188.

Mortensen, D. T. and Nagypál, É. (2007), 'More on unemployment and vacancy fluctuations', Review of Economic Dynamics 10(3), 327-347.

Mortensen, D. T. and Pissarides, C. A. (1994), 'Job creation and job destruction in the theory of unemployment', Review of Economic Studies 61(3), 397-415.

Newey, W. K. and West, K. D. (1987), 'A simple, positive semidefinite, heteroskedasticity and autocorrelation consistent covariance matrix', Econometrica 55(3), 703-708.

Newey, W. K. and Smith, R. J. (2004), 'Higher order properties of GMM and generalized empirical likelihood estimators', Econometrica 72(1), 219-255.

Pissarides, C. A. (1985), 'Short-run equilibrium dynamics of unemployment, vacancies, and real wages', American Economic Review 75(4), 676-690.

Pissarides, C. A. (2009), 'The unemployment volatility puzzle: Is wage stickiness the answer?', Econometrica 77(5), 1339-1369.

Robin, J.-M. (2011), 'On the dynamics of unemployment and wage distributions', Econometrica 79(5), 1327-1355.

Rudanko, L. (2009), 'Labor market dynamics under long-term wage contracting', Journal of Monetary Economics 56(2), 170-183.

Rudanko, L. (2011), Aggregate and idiosyncratic risk in a frictional labor market', American Economic Review 101(6), 2823-2843.

Rudd, J. and Whelan, K. (2006), 'Can rational expectations sticky-price models explain inflation dynamics?', American Economic Review 96(1), 303-320.

Shapiro, C. and Stiglitz, J. E. (1984), 'Equilibrium unemployment as a worker discipline device', American Economic Review 74(3), 433-444.

Shimer, R. (2004), 'The consequences of rigid wages in search models', Journal of the European Economic Association 2(2-3), 469-479.

Shimer, R. (2005), 'The cyclical behavior of equilibrium unemployment and vacancies', American Economic Review 95(1), 25-49. 
Stock, J. H. and Wright, J. H. (2000), 'GMM with weak identification', Econometrica 68(5), 10551096.

Stock, J. H., Wright, J. H. and Yogo, M. (2002), 'GMM, weak instruments, and weak identification', Journal of Business and Economic Statistics 20, 518-530.

Thomas, J. and Worrall, T. (1988), 'Self-enforcing wage contracts', Review of Economic Studies 55(4), 541-554.

Yashiv, E. (2000), 'The determinants of equilibrium unemployment', American Economic Review 90(5), 1297-1322.

Yashiv, E. (2006), 'Evaluating the performance of the search and matching model', European Economic Review 50, 909-936. 


\section{Appendix A Full theoretical model}

\section{A.1 Basic framework}

The path of output in a match is determined by a random draw at the time the match is formed but may change over time (because, for example, of a general increase in productivity) at a rate common to all matches. The distribution of match productivity is such that it is always worthwhile to form a match when a vacant job and an unemployed worker meet. Match productivity in match $k$ at time $t$ is denoted $p_{t}^{k}$. In the basic model, separations occur only for exogenous reasons and at the same rate for all matches - there is no on the job search. Thus the distribution of productivity in actual matches is the same as the distribution of the productivity of potential matches. Denote by $J_{\tau, t}^{k}$ the expected present value of current and future profits at $t$ to a firm from having a filled job in match $k$ whose wage was most recently negotiated at $\tau \leq t$. This equals (i) output $p_{t}^{k}$ net of wage costs $w_{\tau, t}^{k}$ for period $t$, plus (ii) the expected present value of profits $\tilde{J}_{\tau, t+1}^{k}$ from period $t+1$ on (when taking account of the possibility that the wage is renegotiated at $t+1$ ), discounted by the discount factor $\delta_{t}$ and the probability $\left(1-s_{t+1}\right)$ that the relationship is not ended before production at $t+1$ because the match is destroyed for exogenous reasons, plus (iii) the expected payoff $V_{t+1}$ (if non-negative) of going back into the market for another employee if the match is destroyed. (A new match results in a new productivity draw and negotiation of a new wage, so $V_{t+1}$ does not depend on $k$.) Thus

$$
J_{\tau, t}^{k}=p_{t}^{k}-w_{\tau, t}^{k}+\delta_{t} E_{t}\left\{\left(1-s_{t+1}\right) \tilde{J}_{\tau, t+1}^{k}+s_{t+1} \max \left[0, V_{t+1}\right]\right\}, \text { for all } k, t \geq \tau,
$$

where $E_{t}$ is the expectation operator conditional on information available at $t$. Hagedorn and Manovskii (2008) and Hall and Milgrom (2008) assume $s_{t+1}$ constant for all $t$. Here we allow for separation shocks in view of the importance Mortensen and Nagypál (2007) attribute to these.

In Hagedorn and Manovskii (2008), a new match at $t$ results in employment starting at $t+1$ and thus expected future profit $\delta_{t} E_{t} \tilde{J}_{t, t+1}$, where $\tilde{J}_{\tau, t}$ (with no superscript and $t>\tau$ ) is the average, over the distribution of productivities of matches that negotiated the wage most recently at $\tau<t$, of firms' payoffs from such matches from $t$ on. For the empirical work, we are restricted to quarterly data, for which a one-period delay between matching and employment starting may seem implausibly long. Hagedorn and Manovskii (2011), however, argue for a time to build between the decision to create a vacancy and the possibility of a job becoming productive, for which they find 3 months appropriate. With the quarterly data used here, that corresponds to a one-period time to build. To avoid being overly prescriptive, we allow for a one-period delay with probability $1-\kappa$ and zero delay with probability $\kappa$. The expected present value $V_{t}$ of creating a vacancy at $t$ for 
which productivity is not yet determined and the wage is to be negotiated is then

$$
V_{t}=-c_{t}+q_{t}\left[\kappa J_{t, t}+(1-\kappa) \delta_{t} E_{t} \tilde{J}_{t, t+1}\right]+\left(1-q_{t}\right) \delta_{t} E_{t} \max \left[0, V_{t+1}\right] \text {, for all } t,
$$

where $c_{t}$ is the vacancy posting cost that must be incurred at the start of period $t$ to create a vacancy, $q_{t}$ is the probability the vacancy is matched with a worker, $J_{t, t}$ (with no superscript) is the expectation at $t$ of a firm's payoff from $t$ on from a new match at $t$ before match productivity is known and the wage bargained, and $\tilde{J}_{\tau, t}$ (with no superscript and $t>\tau$ ) is the average, over the distribution of productivities of matches that negotiated wages most recently at $\tau<t$, of firms' payoffs from $t$ on from such matches. (If wages are not negotiated every period, (A.2) implies that a match at $t$ with employment starting at $t+1$ has its match productivity drawn, and its wage negotiated, at $t$. Match productivity then changes at the same rate between $t$ and $t+1$, and the wage has the same possibility for renegotiation at $t+1$, as in continuing matches. If wages are negotiated every period, $\tilde{J}_{t, t+1}=J_{t+1, t+1}$ so no such assumption is implied.) Free entry of vacancies when (as in the data) new vacancies are created at each date implies

$$
V_{t}=0, \text { for all } t
$$

For a worker in match $k$ at $t$ whose wage was most recently negotiated at $\tau \leq t$, the expected present value of employment $W_{\tau, t}^{k}$ is given by

$$
W_{\tau, t}^{k}=w_{\tau, t}^{k}+\delta_{t} E_{t}\left[\left(1-s_{t+1}\right) \tilde{W}_{\tau, t+1}^{k}+s_{t+1} U_{t+1}\right], \text { for all } k, t \geq \tau,
$$

where $\tilde{W}_{\tau, t+1}^{k}$ is the expected present value of employment from period $t+1$ on (when taking account of the possibility that the wage is renegotiated at $t+1)$ and $U_{t+1}$ is the expected present value of starting period $t+1$ unemployed, an event that happens with the probability $s_{t+1}$ that the job comes to an end for exogenous reasons. The probability that a worker unemployed at $t$ finds a job in the matching process at $t$ is denoted by $f_{t}$, the value of non-work activity (including any unemployment benefit) by $z_{t}$. The expected present value $U_{t}$ of seeking a match at $t$ is then

$$
U_{t}=f_{t}\left[\kappa W_{t, t}+(1-\kappa)\left(z_{t}+\delta_{t} E_{t} \tilde{W}_{t, t+1}\right)\right]+\left(1-f_{t}\right)\left(z_{t}+\delta_{t} E_{t} U_{t+1}\right), \text { for all } t,
$$

where $W_{t, t}$ (with no superscript) is the expectation at $t$ of a worker's payoff from $t$ on from a new match at $t$ before match productivity is known and the wage bargained, and $\tilde{W}_{\tau, t}$ (with no superscript and $t>\tau$ ) is the average, over the distribution of productivities of matches that negotiated the wage most recently at $\tau<t$, of workers' payoffs from $t$ on from such matches. The righthand side of (A.5) can be interpreted as follows. With probability $f_{t}$, the worker is hired at $t$ and receives expected future utility $\left[\kappa W_{t, t}+(1-\kappa)\left(z_{t}+\delta_{t} E_{t} \tilde{W}_{t, t+1}\right)\right]$ from being matched. With 
probability $1-f_{t}$ the worker is not hired at $t$ and receives utility $z_{t}$ for period $t$ plus the expected utility from starting period $t+1$ unmatched.

Pissarides (2009) has argued for an extension of matching models to allow for fixed costs incurred after matching has occurred, such as training, negotiation, or one-off administrative costs. For our purposes, this specification corresponds to replacing the vacancy posting $\operatorname{cost}$ term $c_{t}$ in (A.2) by the composite cost $c_{t}+q_{t} H_{t}$, where $H_{t}$ is the fixed cost incurred by the firm after meeting a new worker but before the wage is agreed (compare with Pissarides (2009, p. 1364)). To save on notation, we retain the representation in (A.2) for developing the theory and make the appropriate adjustment for the empirical analysis.

This model nests the case of homogeneous productivity and no wage rigidity by setting $p_{t}^{k}=$ $p_{t}, w_{\tau, t}^{k}=w_{t}, J_{\tau, t}^{k}=\tilde{J}_{\tau, t}^{k}=\tilde{J}_{\tau, t}=J_{t, t}$ and $W_{\tau, t}^{k}=\tilde{W}_{\tau, t}^{k}=\tilde{W}_{\tau, t}=W_{t, t}$ for all $k, \tau$ and $t \geq \tau$.

\section{A.2 Wage determination in the basic model}

\section{A.2.1 Nash bargaining}

Most of the literature on matching models follows Mortensen and Pissarides (1994) in modelling wage determination by the Nash bargaining solution. The generalized form of that solution for the wage negotiated for match $k$ at $t$ is

$$
W_{t, t}^{k}-U_{t}=\frac{\beta}{1-\beta}\left(J_{t, t}^{k}-V_{t}\right), \text { for } \beta \in[0,1),
$$

where $\beta /(1-\beta)$ is the bargaining power of workers relative to that of firms. With the free entry condition $V_{t}=0$, (A.6) reduces to the formulation in Hagedorn and Manovskii (2008)

$$
W_{t}^{k}-U_{t}=\frac{\beta}{1-\beta} J_{t}^{k}, \text { for } \beta \in[0,1) .
$$

\section{A.2.2 Credible bargaining}

Hall and Milgrom (2008) develop an alternative to the standard Nash bargain in which there is positive probability, here denoted $\alpha$, that negotiations break down irrevocably each time a new offer is made. They also include a cost to making an offer that we here denote by $\gamma_{t}^{f}$ for each offer the firm makes in period $t$ and $\gamma_{t}^{w}$ for each offer the worker makes in period $t$. (The specification in Hall and Milgrom (2008) corresponds to $\gamma_{t}^{w}=0$ but, for reasons that will become apparent, it is useful to allow $\gamma_{t}^{w}>0$.) If negotiations break down, the parties search for alternative matches.

In Hall and Milgrom (2008), the parties alternate in making offers, starting with the firm, with at most one offer made each period. Hall and Milgrom (2008) envisage each period as corresponding to a day. With the data available, we are constrained to having each period correspond to a quarter, 
so the assumption of at most one offer per period seems implausible. For this reason, we generalize the model to allow offers at fixed intervals that may be less than a whole period. Consider an offer from the firm in match $k$ at time $\eta(0 \leq \eta<1)$ between $t$ and $t+1$ that would yield the worker present value payoff $W_{t+\eta, t+\eta}^{k}$. The worker will accept that offer if $W_{t+\eta, t+\eta}^{k}$ is at least as great as the payoff from rejecting the offer, having negotiations break down with probability $\alpha$ and receiving payoff $U_{t+\eta}$ of seeking an alternative match, but otherwise making a counter-offer resulting in expected present value payoff denoted $\hat{W}_{t+\eta}^{k}$. Recognizing this, the firm will make the lowest offer satisfying that requirement, which gives the indifference condition

$$
W_{t+\eta, t+\eta}^{k}=\alpha U_{t+\eta}+(1-\alpha) \hat{W}_{t+\eta}^{k}, \quad \eta \in[0,1) .
$$

Symmetrically, the firm will accept an offer with present value payoff $J_{t+\eta}^{\prime k}$ made by the worker at time $\eta(0 \leq \eta<1)$ between $t$ and $t+1$ if $J_{t+\eta}^{\prime k}$ is at least as great as the payoff from rejecting the offer, having negotiations break down with probability $\alpha$ and receiving payoff $V_{t+\eta}$ of seeking an alternative match, but otherwise making a counter-offer resulting in expected present value payoff denoted $\hat{J}_{t+\eta}^{k}$. Recognizing this, the worker will make the lowest offer satisfying that requirement, which gives the indifference condition

$$
J_{t+\eta}^{\prime k}=\alpha V_{t+\eta}+(1-\alpha) \hat{J}_{t+\eta}^{k}, \quad \eta \in[0,1)
$$

In Hall and Milgrom (2008), the firm makes the first offer and in equilibrium that offer is always accepted, so the bargained outcome corresponds to $W_{t+\eta, t+\eta}^{k}$ for $\eta=0$.

In the specification in Hall and Milgrom (2008) with only one offer per period,

$$
\hat{J}_{t}^{k}=\delta_{t} E_{t}\left(-\gamma_{t+1}^{f}+J_{t+1, t+1}^{k}\right) ; \quad \hat{W}_{t}^{k}=z_{t}+\delta_{t} E_{t}\left(-\gamma_{t+1}^{w}+W_{t+1}^{\prime k}\right),
$$

where $W_{t+1}^{\prime k}$ is the payoff to the worker from making an offer at $t+1$. The alternative we consider here, which seems more appropriate with periods of a quarter, is to let the time interval between offers go to zero. Then

$$
\hat{J}_{t}^{k}=-\gamma_{t}^{f}+J_{t, t}^{k} ; \quad \hat{W}_{t}^{k}=-\gamma_{t}^{w}+W_{t}^{\prime k} .
$$

In that case, the indifference conditions (A.8) and (A.9) with $\eta=0$ can be solved to give the following sharing rule as an alternative to (A.6):

$$
W_{t, t}^{k}-U_{t}=(1-\alpha)\left(J_{t, t}^{k}-V_{t}\right)+\frac{1-\alpha}{\alpha} \gamma_{t},
$$

where $\gamma_{t}=(1-\alpha) \gamma_{t}^{f}-\gamma_{t}^{w}$. Note that $\gamma_{t}^{f}$ and $\gamma_{t}^{w}$ cannot be separately identified from (A.12). But permitting $\gamma_{t}^{w}>0$ allows the model to be consistent with an estimated $\gamma_{t}<0$. 


\section{A.2.3 Nesting Nash and credible bargaining}

The Nash and credible bargaining outcomes (A.6) and (A.12) are special cases of the more general formulation

$$
W_{t, t}^{k}-U_{t}=\lambda\left(J_{t, t}^{k}-V_{t}\right)+\frac{\lambda}{1-\lambda} \gamma_{t}
$$

with the models satisfying the restrictions

$$
\begin{aligned}
& \text { Nash bargaining (A.6) }: \lambda=\frac{\beta}{1-\beta} \in[0, \infty) ; \gamma_{t}=0 ; \\
& \text { Credible bargaining (A.12) }: \lambda=1-\alpha \in[0,1) .
\end{aligned}
$$

Averaged over all match productivities, (A.13) becomes

$$
W_{t, t}-U_{t}=\lambda\left(J_{t, t}-V_{t}\right)+\frac{\lambda}{1-\lambda} \gamma_{t},
$$

where we have made use of the linearity property of expectations. ${ }^{10}$

\section{A.2.4 Wages bargained every period}

With all wages bargained every period, the average wage $w_{t}$ is just the average of the wages for each individual match $k$ given by (A.13). Because, from (A.1) and (A.4), $J_{t, t}^{k}$ and $W_{t, t}^{k}$ are linear in $w_{t, t}^{k}$, the average wage is given by (A.15). In this case, (A.15) can be combined with (A.2), (A.3) and (A.5) to yield wage equation (1) for the average wage. For Nash bargaining, $\lambda=\beta /(1-\beta)$ and $\gamma_{t}=0$ so (1) can be written

$$
w_{t}=\beta p_{t}+(1-\beta) z_{t}+\beta c_{t} \frac{f_{t}}{q_{t}\left(1-f_{t} \kappa\right)} .
$$

When $\kappa=0$, (A.16) is exactly the wage equation in Hagedorn and Manovskii (2008).

\section{A.2.5 Wage equation independent of vacancy creation equation}

A wage equation that is independent of the vacancy creation equation can be derived as follows. From the free entry condition (A.3), $V_{t}=0$ for all $t$. With the wage for every job bargained in every period, $\tilde{J}_{\tau, t}=J_{t, t}$ for $\tau \leq t$. With those specifications, (A.1) averaged over all match productivities becomes

$$
J_{t, t}=p_{t}-w_{t}+\delta_{t} E_{t}\left(1-s_{t+1}\right) J_{t+1, t+1}, \text { for all } t .
$$

\footnotetext{
${ }^{10}$ This follows by Tonelli's theorem, see Billingsley (1995, Theorem 18.3).
} 
Also, with the wage for every job bargained in every period, $\tilde{W}_{\tau, t}=W_{t, t}$ for $\tau \leq t$. Then (A.4) averaged over all match productivities and (A.5) can be jointly solved forward to write

$$
W_{t, t}-U_{t}=E_{t} \sum_{n=0}^{\infty} \delta_{t, n}^{\kappa}\left(1-f_{t+n} \kappa\right)\left(w_{t+n}-z_{t+n}\right)
$$

where $\delta_{t, n}^{\kappa}=\prod_{i=1}^{n} \delta_{t+i}^{\kappa}$, with $\delta_{t, 0}^{\kappa}=1$, and $\delta_{t}^{\kappa}=\delta_{t-1}\left(1-s_{t}-f_{t-1}+\kappa s_{t} f_{t-1}\right)$. These two conditions can be used with (A.15) to yield the wage equation (2).

\section{A.3 Extensions to the basic model}

Two important generalizations of the basic model in the literature are to on the job search and to wages that are not negotiated every period.

\section{A.3.1 On the job search}

In the Hagedorn and Manovskii (2013) model of on the job search, wage determination in match $k$ takes, up to a log-linear approximation, the form (see their equation (1))

$$
w_{t, t}^{k}=\left(p_{t}^{k}\right)^{\zeta}\left(\vartheta_{t}\right)^{\rho}, \quad \text { for all } k, t
$$

where $\vartheta_{t}$ is a business cycle indicator that incorporates labour market tightness. For empirical purposes, Hagedorn and Manovskii (2013, eq. (35)) normalize $\zeta=1$ because it is not identified separately from the standard deviation of the distribution of productivities. With $\zeta=1$ and averaging over $k$, (A.19) corresponds to (A.16) with

$$
\left(\vartheta_{t}\right)^{\rho}=(1-\beta) \frac{z_{t}}{p_{t}}+\beta\left[1+\frac{c_{t}}{p_{t}} \frac{f_{t}}{q_{t}\left(1-f_{t} \kappa\right)}\right] .
$$

The formulation in (A.19) does not take explicit account of the possibility that the measured productivity process will be influenced by selection over the business cycle, as workers search on the job for more productive matches. In Appendix C, we write down a model that explicitly takes this into account and derive the resulting wage equation under the assumption that $\kappa=1$. This is given by:

$$
w_{t}=\frac{z_{t}}{1+\lambda}+\frac{\lambda}{1+\lambda}\left[p_{t}+\frac{f_{t}}{1-f_{t}} \frac{c_{t} / q_{t}-\varrho_{t} \tilde{J}_{t}}{1-\varrho_{t}}\right]-X_{t}, \text { for all } t,
$$

where $\varrho_{t}$ is the probability that a job is filled with a previously employed worker, $\tilde{J}_{t}$ is the average value of a job filled with a previously employed worker, and $X_{t}$ is a term that has no impact on the ensuing discussion. We cannot measure the variables in $\tilde{J}_{t}$ and $X_{t}$ from the available data, 
so we are not able to provide direct estimates of (A.20). But the following argument shows that specification (A.20) cannot be expected to account for the type of persistence that we observe in the data.

Consider the dynamic effect on wages of a shock to the productivity distribution. Suppose that the distribution of productivities in period $t-1$ is untypically favourable to high productivity. This implies that $w_{t-1}$ is untypically high, since it is positively related to $p_{t-1}$. If this also led to $w_{t}$ being untypically high, it would result in positive persistence in wages, which would be consistent with what we see in the data. Equation (A.20) shows that the impact of this shock on $w_{t}$ comes from $\tilde{J}_{t}$, since all other terms are unaffected by a purely transitory shock in the productivity process in period $t-1$. The term $\tilde{J}_{t}$ depends positively on the distribution of productivities in period $t-1$, in the sense that higher productivities in period $t-1$ will lead to a higher threshold for a successful new match in period $t$ with an already employed worker, thus making the average value of jobs filled with already employed workers higher. Therefore, since $w_{t}$ is decreasing in $\tilde{J}_{t}$, and the latter rises in response to this productivity shock, $w_{t}$ falls, and this is in the opposite direction of what we need in order fit the data.

\section{A.3.2 Wage rigidity}

Following Pissarides (2009), we model wage rigidity as applying only to continuing matches, with wages for new matches all negotiated. The form of wage rigidity is that developed by Gertler and Trigari (2009) but applied only to continuing, not new, matches. Persistence takes the form of a fixed probability $1-\psi$ that a firm renegotiates its wage in any period. In the absence of such renegotiation, the wage remains the same as in the previous period. Thus the wage at $t$ for a match with wage most recently negotiated at $\tau \leq t-1$ is

$$
\begin{array}{ll}
w_{t, t}^{k}, & \text { with probability } 1-\psi, \\
\pi_{t}^{-\mu} w_{\tau, t-1}^{k}, & \text { with probability } \psi,
\end{array}, \psi, \mu \in[0,1],
$$

where $\pi_{t}$ is the ratio of prices at $t$ to prices at $t-1$, which we incorporate to allow for the possibility that the previous period's wage may be adjusted automatically in response to inflation, with $\mu$ a parameter to be estimated. With wage rigidity of the form in (A.21),

$$
\begin{aligned}
\tilde{J}_{\tau, t}^{k} & =(1-\psi) J_{t, t}^{k}+\psi J_{\tau, t}^{k}=J_{t, t}^{k}-\psi\left(J_{t, t}^{k}-J_{\tau, t}^{k}\right) \\
\tilde{W}_{\tau, t}^{k} & =(1-\psi) W_{t, t}^{k}+\psi W_{\tau, t}^{k}=W_{t, t}^{k}-\psi\left(W_{t, t}^{k}-W_{\tau, t}^{k}\right) .
\end{aligned}
$$

(Recall that $\tilde{J}_{\tau, t}^{k}$ and $\tilde{W}_{\tau, t}^{k}$ refer to matches with wage negotiated at $\tau$ but not renegotiated before $t$.) With wages negotiated in all new matches, (A.1), (A.2), (A.4) and (A.5) continue to apply. 
Manipulation of these conditions gives

$$
\begin{aligned}
& J_{t+1, t+1}^{k}-J_{t, t+1}^{k} \\
& \quad=-\left(W_{t+1, t+1}^{k}-W_{t, t+1}^{k}\right) \\
& \quad=\left(\pi_{t+1}^{-\mu} w_{t, t}^{k}-w_{t+1, t+1}^{k}\right) E_{t+1}\left[\sum_{i=1}^{\infty} \prod_{j=2}^{i}\left(\delta_{t+j-1}\left(1-s_{t+j}\right) \psi \pi_{t+j}^{-\mu}\right)\right],
\end{aligned}
$$

with the convention that the product term equals 1 for $i<j$. For a newly-bargained wage, (A.13) applies. Moreover, with the formulation in (A.21), the distribution of match productivities for new bargains is the same as that for all vacancies so the average newly-bargained wage is still given by (A.15).

\section{A.4 Empirical wage equation}

Let $w_{t}^{*}$ denote the average newly-negotiated wage at $t$ (that is, the average of $w_{t, t}^{k}$ for matches $k$ negotiating wages at $t$ ). Then, from (A.1) for $\tau=t$ averaged over all match productivities and with $V_{t+1} \geq 0$ for all $t$ (as it must be when the free entry condition (A.3) holds for all $t$ ),

$$
J_{t, t}=p_{t}-w_{t}^{*}+\delta_{t} E_{t}\left[\left(1-s_{t+1}\right) \tilde{J}_{t, t+1}+s_{t+1} V_{t+1}\right], \text { for all } t .
$$

This can be combined with (A.2) to give

$$
\begin{aligned}
J_{t, t}-V_{t}= & \left(1-q_{t} \kappa\right)\left(p_{t}-w_{t}^{*}\right)+c_{t} \\
& +\delta_{t} E_{t}\left[\left(1-s_{t+1}-q_{t}+q_{t} \kappa s_{t+1}\right)\left(\tilde{J}_{t, t+1}-V_{t+1}\right)\right] .
\end{aligned}
$$

Use of (A.22) in (A.27) gives

$$
\begin{aligned}
& J_{t, t}-V_{t} \\
& =\left(1-q_{t} \kappa\right)\left(p_{t}-w_{t}^{*}\right)+c_{t} \\
& \quad+\delta_{t} E_{t}\left[\left(1-s_{t+1}-q_{t}+q_{t} \kappa s_{t+1}\right)\left(J_{t+1, t+1}-V_{t+1}-\psi\left(J_{t+1, t+1}-J_{t, t+1}\right)\right)\right] .
\end{aligned}
$$

Similarly, from (A.4) for $\tau=t$ averaged over all match productivities,

$$
W_{t, t}=w_{t}^{*}+\delta_{t} E_{t}\left[\left(1-s_{t+1}\right) \tilde{W}_{t, t+1}+s_{t+1} U_{t+1}\right] \text {, for all } t .
$$


This can be combined with (A.5) to give

$$
\begin{aligned}
W_{t, t}-U_{t}= & \left(1-f_{t} \kappa\right)\left(w_{t}^{*}-z_{t}\right) \\
& +\delta_{t} E_{t}\left[\left(1-s_{t+1}-f_{t}+\kappa f_{t} s_{t+1}\right)\left(\tilde{W}_{t, t+1}-U_{t+1}\right)\right] .
\end{aligned}
$$

Use of (A.23) in (A.30) gives

$$
\begin{aligned}
W_{t, t}-U_{t}= & \left(1-f_{t} \kappa\right)\left(w_{t}^{*}-z_{t}\right)+\delta_{t} E_{t}\left\{\left(1-s_{t+1}-f_{t}\right.\right. \\
& \left.\left.+\kappa f_{t} s_{t+1}\right)\left[W_{t+1, t+1}-U_{t+1}-\psi\left(W_{t+1, t+1}-W_{t, t+1}\right)\right]\right\} .
\end{aligned}
$$

Use of (A.15) forwarded one period and (A.24) in this allows it to be written

$$
\begin{aligned}
& W_{t, t}-U_{t} \\
& =\left(1-f_{t} \kappa\right)\left(w_{t}^{*}-z_{t}\right)+\delta_{t} E_{t}\left\{\left(1-s_{t+1}-f_{t}\right.\right. \\
& \left.\left.\quad+\kappa f_{t} s_{t+1}\right)\left[\lambda\left(J_{t+1, t+1}-V_{t+1}\right)+\frac{\lambda}{1-\lambda} \gamma_{t+1}+\psi\left(J_{t+1, t+1}-J_{t, t+1}\right)\right]\right\} .
\end{aligned}
$$

Use of (A.28), (A.31) and the free entry condition (A.3) in (A.15) can, with some manipulation (see Appendix B), be used to derive the wage equation (3) for newly formed matches in the text.

Empirical implementation of (3) requires a data series for the average newly-negotiated wage $w_{t}^{*}$. Under the assumptions of the model, continuing matches for which wages are renegotiated have a random sample of match productivities. Thus, a series for the average newly-negotiated wage consistent with the model can be derived using an approximation suggested by Gertler and Trigari (2009) based on the law of large numbers. Let $j_{t}$ denote employment at $t$, which equals the number of filled jobs. The total number of matches negotiating their wage at $t$ comprises new matches created at $t m_{t}=j_{t}-\left(1-s_{t}\right) j_{t-1}$, plus continuing matches that renegotiate the wage at $t,(1-\psi)\left(1-s_{t}\right) j_{t-1}$. Hence the total wage bill at $t$, with $w_{t}$ the average wage in all matches at $t$, is

$$
\begin{aligned}
w_{t} j_{t}= & \left\{\left[j_{t}-\left(1-s_{t}\right) j_{t-1}\right]+(1-\psi)\left(1-s_{t}\right) j_{t-1}\right\} w_{t}^{*}+\psi\left(1-s_{t}\right) j_{t-1} \pi_{t}^{-\mu} w_{t-1} \\
& =\left[j_{t}-\psi\left(1-s_{t}\right) j_{t-1}\right] w_{t}^{*}+\psi\left(1-s_{t}\right) j_{t-1} \pi_{t}^{-\mu} w_{t-1} .
\end{aligned}
$$

So the average newly-negotiated wage is given by (4). 


\section{Appendix B Derivations of equations}

Table 6 gives definitions of variables in the theoretical models, Table 7 definitions of parameters.

\section{B.1 Derivation of equation (A.12)}

With the specification in (A.11), (A.8) and (A.9) with $\eta=0$ become

$$
\begin{aligned}
W_{t, t}^{k} & =\alpha U_{t}+(1-\alpha)\left(-\gamma_{t}^{w}+W_{t}^{\prime k}\right) \\
J_{t}^{\prime k} & =\alpha V_{t}+(1-\alpha)\left(-\gamma_{t}^{f}+J_{t, t}^{k}\right) .
\end{aligned}
$$

The terms in $W_{t}^{\prime k}$ and $J_{t}^{\prime k}$ in (A.32) and (A.33) can be eliminated in the following way. Multiply (A.33) by $1-\alpha$ and subtract it from (A.32) to get

$$
W_{t, t}^{k}-(1-\alpha) J_{t}^{\prime k}=\alpha U_{t}+(1-\alpha)\left(-\gamma_{t}^{w}+W_{t}^{\prime k}\right)-\alpha(1-\alpha) V_{t}-(1-\alpha)^{2}\left(-\gamma_{t}^{f}+J_{t, t}^{k}\right)
$$

Next note that $W_{t}^{\prime k}+J_{t}^{\prime k}=W_{t, t}^{k}+J_{t, t}^{k}$ necessarily, so this can be written

$$
W_{t, t}^{k}=\alpha U_{t}-(1-\alpha) \gamma_{t}^{w}+(1-\alpha)\left(W_{t, t}^{k}+J_{t, t}^{k}\right)-\alpha(1-\alpha) V_{t}-(1-\alpha)^{2}\left(-\gamma_{t}^{f}+J_{t, t}^{k}\right)
$$

or, subtracting $W_{t, t}^{k}$ from both sides

$$
0=\alpha U_{t}-(1-\alpha) \gamma_{t}^{w}-\alpha W_{t, t}^{k}+(1-\alpha)(1-(1-\alpha)) J_{t, t}^{k}-\alpha(1-\alpha) V_{t}+(1-\alpha)^{2} \gamma_{t}^{f} .
$$

This can be rewritten as (A.12).

\section{B.2 Derivation of equation (1)}

Equation (1) is a special case of (3) with $\psi=0$ and $w_{t}^{*}=w_{t}$, as is appropriate when all wages are bargained every period.

\section{B.3 Derivation of equation (A.18)}

Equation (A.18) follows from solving forward equation (A.30) with, as appropriate when the wage for all jobs is bargained every period, $w_{t}^{*}=w_{t}$ and $E_{t} \tilde{W}_{t, t+1}=E_{t} W_{t+1, t+1}$. 


\begin{tabular}{|c|l|}
\hline Variable & Description \\
\hline$p_{t}^{k}$ & productivity in match $k$ at $t$ \\
$p_{t}$ & average productivity in matches at $t$ \\
$\bar{p}_{t}$ & trend productivity at $t$ \\
$\tilde{p}_{t}$ & $p_{t} / \bar{p}_{t}$ \\
$w_{\tau, t}^{k}$ & wage in match $k$ at $t$ negotiated at $\tau$ \\
$w_{t}$ & average wage in matches at $t$ \\
$w_{t}^{*}$ & average of wages newly-negotiated at $t$ \\
$\delta_{t}$ & discount factor applied to $t+1$ at $t$ \\
$s_{t}$ & match separation probability at $t$ \\
$c_{t}$ & vacancy posting cost at $t$ \\
$\gamma_{t}^{f}$ & cost to firm of making an offer at $t$ with credible bargaining \\
$\gamma_{t}^{w}$ & cost to worker of making an offer at $t$ with credible bargaining \\
$\gamma_{t}$ & (1- $\alpha) \gamma_{t}^{f}-\gamma_{t}^{w}$ \\
$H_{t}$ & cost of starting employment at $t$ \\
$q_{t}$ & probability of filling a vacancy at $t$ \\
$f_{t}$ & probability of finding employment at $t$ \\
$z_{t}$ & value of non-work activity at $t$ \\
$\pi_{t}$ & ratio of prices at $t$ to prices at $t-1$ \\
$J_{\tau, t}^{k}$ & payoff to firm at $t$ from match $k$ with wage negotiated at $\tau$ \\
$J_{\tau, t}$ & average payoff to firms at $t$ from matches with wage negotiated at $\tau$ \\
$\tilde{J}_{\tau, t}^{k}$ & expected $J_{\tau, t}^{k}$ before possible renegotiation at $t$ \\
$\tilde{J}_{\tau, t}$ & expected $J_{\tau, t}$ before possible renegotiation at $t$ \\
$W_{\tau, t}^{k}$ & payoff to worker at $t$ from match $k$ with wage negotiated at $\tau$ \\
$W_{\tau, t}$ & average payoff to workers at $t$ from matches with wage negotiated at $\tau$ \\
$\tilde{W}_{\tau, t}^{k}$ & expected $W_{\tau, t}^{k}$ before possible renegotiation at $t$ \\
$\tilde{W}_{\tau, t}$ & expected $W_{\tau, t}$ before possible renegotiation at $t$ \\
$V_{t}$ & value of unfilled vacancy at $t$ \\
$U_{t}$ & payoff to worker from seeking match at $t$ \\
$\delta_{t}^{\kappa}$ & $\delta_{t-1}\left(1-s_{t}-f_{t-1}+\kappa s_{t} f_{t-1}\right)$ \\
\hline
\end{tabular}

Table 6: Variables in theoretical models

\begin{tabular}{|c|l|}
\hline Parameter & Definition \\
\hline$\kappa$ & probability that employment starts at $t$ for new match at $t$ \\
$\beta$ & worker bargaining power in Nash bargain \\
$\alpha$ & probability of negotiation breakdown with credible bargaining \\
$\lambda$ & $\beta /(1-\beta)$ with Nash bargaining; $1-\alpha$ with credible bargaining \\
$\psi$ & degree of wage rigidity (equals 0 if none) \\
$\mu$ & proportion of unrenegotiated wages set in nominal terms \\
\hline
\end{tabular}

Table 7: Parameters in theoretical models 


\section{B.4 Derivation of equation (2)}

Multiply (A.17) through by $\lambda$ and use (A.15) to substitute for $J_{t, t}$ and $J_{t+1, t+1}$ to get

$$
W_{t, t}-U_{t}-\frac{\lambda}{1-\lambda} \gamma_{t}=\lambda\left(p_{t}-w_{t}\right)+\delta_{t} E_{t}\left[\left(1-s_{t+1}\right)\left(W_{t+1, t+1}-U_{t+1}-\frac{\lambda}{1-\lambda} \gamma_{t+1}\right)\right] .
$$

Use of (A.18) to substitute for $W_{t, t}-U_{t}$ and $W_{t+1, t+1}-U_{t+1}$ in (A.34) yields (2).

\section{B.5 Derivation of equations (A.24) and (A.25)}

Let $\tilde{V}_{t}^{k}=\max \left[0, V_{t}^{k}\right]$ for notational simplicity. From (A.1) for $\tau=t$ and (A.22),

$$
\begin{aligned}
J_{t, t+1}^{k}= & p_{t+1}^{k}-\pi_{t+1}^{-\mu} w_{t, t}^{k}+\delta_{t+1} E_{t+1}\left[\left(1-s_{t+2}\right) \tilde{J}_{t, t+2}^{k}+s_{t+2} \tilde{V}_{t+2}^{k}\right] \\
= & p_{t+1}^{k}-\pi_{t+1}^{-\mu} w_{t, t}^{k} \\
& +\delta_{t+1} E_{t+1}\left\{\left(1-s_{t+2}\right)\left[(1-\psi) J_{t+2, t+2}^{k}+\psi J_{t, t+2}^{k}\right]+s_{t+2} \tilde{V}_{t+2}^{k}\right\} .
\end{aligned}
$$

Moreover, from (A.1) with the wage negotiated at $t+1$ and (A.22),

$$
\begin{aligned}
J_{t+1, t+1}^{k}= & p_{t+1}^{k}-w_{t+1, t+1}^{k}+\delta_{t+1} E_{t+1}\left[\left(1-s_{t+2}\right) \tilde{J}_{t+1, t+2}^{k}+s_{t+2} \tilde{V}_{t+2}^{k}\right] \\
= & p_{t+1}^{k}-w_{t+1, t+1}^{k} \\
& \quad+\delta_{t+1} E_{t+1}\left\{\left(1-s_{t+2}\right)\left[(1-\psi) J_{t+2, t+2}^{k}+\psi J_{t+1, t+2}^{k}\right]+s_{t+2} \tilde{V}_{t+2}^{k}\right\} .
\end{aligned}
$$

Hence,

$$
J_{t+1, t+1}^{k}-J_{t, t+1}^{k}=\pi_{t+1}^{-\mu} w_{t, t}^{k}-w_{t+1, t+1}^{k}+\delta_{t+1} E_{t+1}\left[\left(1-s_{t+2}\right) \psi\left(J_{t+1, t+2}^{k}-J_{t, t+2}^{k}\right)\right] .
$$

Furthermore, again from (A.1) and (A.22),

$$
\begin{aligned}
J_{t, t+2}^{k}= & p_{t+2}^{k}-\pi_{t+2}^{-\mu} \pi_{t+1}^{-\mu} w_{t, t}^{k}+\delta_{t+2} E_{t+2}\left[\left(1-s_{t+3}\right) \tilde{J}_{t, t+3}^{k}+s_{t+3} \tilde{V}_{t+3}^{k}\right] \\
= & p_{t+2}^{k}-\pi_{t+2}^{-\mu} \pi_{t+1}^{-\mu} w_{t, t}^{k} \\
& \quad+\delta_{t+2} E_{t+2}\left\{\left(1-s_{t+3}\right)\left[(1-\psi) J_{t+3, t+3}^{k}+\psi J_{t, t+3}^{k}\right]+s_{t+3} \tilde{V}_{t+3}^{k}\right\}
\end{aligned}
$$


so, with the use of (A.35) forwarded one period,

$$
\begin{aligned}
& J_{t+1, t+2}^{k}-J_{t, t+2}^{k} \\
& =p_{t+2}^{k}-\pi_{t+2}^{-\mu} w_{t+1, t+1}^{k}+\delta_{t+2} E_{t+2}\left\{\left(1-s_{t+3}\right)\left[(1-\psi) J_{t+3, t+3}^{k}+\psi J_{t+1, t+3}^{k}\right]+s_{t+3} \tilde{V}_{t+3}^{k}\right\} \\
& \quad-p_{t+2}^{k}+\pi_{t+2}^{-\mu} \pi_{t+1}^{-\mu} w_{t, t}^{k}-\delta_{t+2} E_{t+2}\left\{\left(1-s_{t+3}\right)\left[(1-\psi) J_{t+3, t+3}^{k}+\psi J_{t, t+3}^{k}\right]+s_{t+3} \tilde{V}_{t+3}^{k}\right\} \\
& =\pi_{t+2}^{-\mu}\left(\pi_{t+1}^{-\mu} w_{t, t}^{k}-w_{t+1, t+1}^{k}\right)+\delta_{t+2} E_{t+2}\left[\left(1-s_{t+3}\right) \psi\left(J_{t+1, t+3}^{k}-J_{t, t+3}^{k}\right)\right] .
\end{aligned}
$$

Use of this in (A.36) gives

$$
\begin{aligned}
J_{t+1, t+1}^{k}-J_{t, t+1}^{k} & =\left(\pi_{t+1}^{-\mu} w_{t, t}^{k}-w_{t+1, t+1}^{k}\right)\left[1+\delta_{t+1} E_{t+1}\left(1-s_{t+2}\right) \psi \pi_{t+2}^{-\mu}\right] \\
& +\delta_{t+1} E_{t+1} \delta_{t+2}\left[\left(1-s_{t+2}\right) \psi\left(1-s_{t+3}\right) \psi\left(J_{t+1, t+3}^{k}-J_{t, t+3}^{k}\right)\right] .
\end{aligned}
$$

Proceeding recursively in this way gives

$$
J_{t+1, t+1}^{k}-J_{t, t+1}^{k}=\left(\pi_{t+1}^{-\mu} w_{t, t}^{k}-w_{t+1, t+1}^{k}\right) E_{t+1}\left[1+\sum_{i=2}^{\infty} \prod_{j=2}^{i}\left(\delta_{t+j-1}\left(1-s_{t+j}\right) \psi \pi_{t+j}^{-\mu}\right)\right] .
$$

With the convention that the product term equals 1 for $i<j$, this can be written as (A.25).

From (A.4) for $\tau=t$ and (A.23),

$$
\begin{aligned}
W_{t, t+1}^{k}= & \pi_{t+1}^{-\mu} w_{t, t}^{k}+\delta_{t+1} E_{t+1}\left[\left(1-s_{t+2}\right) \tilde{W}_{t, t+2}^{k}+s_{t+2} U_{t+2}\right] \\
= & \pi_{t+1}^{-\mu} w_{t, t}^{k} \\
& +\delta_{t+1} E_{t+1}\left\{\left(1-s_{t+2}\right)\left[(1-\psi) W_{t+2, t+2}^{k}+\psi W_{t, t+2}^{k}\right]+s_{t+2} U_{t+2}\right\} .
\end{aligned}
$$

Moreover, from (A.4) with the wage negotiated at $t+1$ and (A.23),

$$
\begin{aligned}
W_{t+1, t+1}^{k} & =w_{t+1, t+1}^{k}+\delta_{t+1} E_{t+1}\left[\left(1-s_{t+2}\right) \tilde{W}_{t+1, t+2}^{k}+s_{t+2} U_{t+2}\right] \\
& =w_{t+1, t+1}^{k}+\delta_{t+1} E_{t+1}\left\{\left(1-s_{t+2}\right)\left[(1-\psi) W_{t+2, t+2}^{k}+\psi W_{t+1, t+2}^{k}\right]+s_{t+2} U_{t+2}\right\} .
\end{aligned}
$$

Hence

$$
W_{t+1, t+1}^{k}-W_{t, t+1}^{k}=w_{t+1, t+1}^{k}-\pi_{t+1}^{-\mu} w_{t, t}^{k}+\delta_{t+1} E_{t+1}\left[\left(1-s_{t+2}\right) \psi\left(W_{t+1, t+2}^{k}-W_{t, t+2}^{k}\right)\right] .
$$

Furthermore, again from (A.4) and (A.23),

$$
\begin{aligned}
W_{t, t+2}^{k} & =\pi_{t+2}^{-\mu} \pi_{t+1}^{-\mu} w_{t, t}^{k}+\delta_{t+2} E_{t+2}\left[\left(1-s_{t+3}\right) \tilde{W}_{t, t+3}^{k}+s_{t+3} U_{t+3}\right] \\
& =\pi_{t+2}^{-\mu} \pi_{t+1}^{-\mu} w_{t, t}^{k}+\delta_{t+2} E_{t+2}\left\{\left(1-s_{t+3}\right)\left[(1-\psi) W_{t+3, t+3}^{k}+\psi W_{t, t+3}^{k}\right]+s_{t+3} U_{t+3}\right\}
\end{aligned}
$$


so, with the use of (A.37) forwarded one period,

$$
\begin{aligned}
& W_{t+1, t+2}^{k}-W_{t, t+2}^{k} \\
& =\pi_{t+2}^{-\mu} w_{t+1, t+1}^{k}+\delta_{t+2} E_{t+2}\left\{\left(1-s_{t+3}\right)\left[(1-\psi) W_{t+3, t+3}^{k}+\psi W_{t+1, t+3}^{k}\right]+s_{t+3} U_{t+3}\right\} \\
& \quad-\pi_{t+2}^{-\mu} \pi_{t+1}^{-\mu} w_{t, t}^{k}-\delta_{t+2} E_{t+2}\left\{\left(1-s_{t+3}\right)\left[(1-\psi) W_{t+3, t+3}^{k}+\psi W_{t, t+3}^{k}\right]+s_{t+3} U_{t+3}\right\} \\
& =\pi_{t+2}^{-\mu}\left(w_{t+1, t+1}^{k}-\pi_{t+1}^{-\mu} w_{t, t}^{k}\right)+\delta_{t+2} E_{t+2}\left[\left(1-s_{t+3}\right) \psi\left(W_{t+1, t+3}^{k}-W_{t, t+3}^{k}\right)\right] .
\end{aligned}
$$

Use of this in (A.38) gives

$$
\begin{aligned}
W_{t+1, t+1}^{k}-W_{t, t+1}^{k} & =\left(w_{t+1, t+1}^{k}-\pi_{t+1}^{-\mu} w_{t, t}^{k}\right)\left[1+\delta_{t+1} E_{t+1}\left(1-s_{t+2}\right) \psi \pi_{t+2}^{-\mu}\right] \\
& +\delta_{t+1} E_{t+1} \delta_{t+2}\left[\left(1-s_{t+2}\right) \psi\left(1-s_{t+3}\right) \psi\left(W_{t+1, t+3}^{k}-W_{t, t+3}^{k}\right)\right] .
\end{aligned}
$$

Proceeding recursively in this way gives

$$
\begin{aligned}
W_{t+1, t+1}^{k}-W_{t, t+1}^{k} & =\left(w_{t+1, t+1}^{k}-\pi_{t+1}^{-\mu} w_{t, t}^{k}\right) E_{t+1}\left[1+\sum_{i=2}^{\infty} \prod_{j=2}^{i}\left(\delta_{t+j-1}\left(1-s_{t+j}\right) \psi \pi_{t+j}^{-\mu}\right)\right] \\
& =\left(w_{t+1, t+1}^{k}-\pi_{t+1}^{-\mu} w_{t, t}^{k}\right) E_{t+1}\left[\sum_{i=1}^{\infty} \prod_{j=2}^{i}\left(\delta_{t+j-1}\left(1-s_{t+j}\right) \psi \pi_{t+j}^{-\mu}\right)\right],
\end{aligned}
$$

again with the convention that the product term equals 1 for $i<j$. (A.24) then follows directly from (A.25). 


\section{B.6 Derivation of equation (A.27)}

From (A.26) and (A.2) with $V_{t+1} \geq 0$ for all $t$,

$$
\begin{aligned}
& J_{t, t}-V_{t} \\
&=\left(1-q_{t} \kappa\right) J_{t, t}+c_{t}-\left[q_{t}(1-\kappa) \delta_{t} E_{t} \tilde{J}_{t, t+1}+\left(1-q_{t}\right) \delta_{t} E_{t} V_{t+1}\right] \\
&=\left(1-q_{t} \kappa\right)\left\{p_{t}-w_{t}^{*}+\delta_{t} E_{t}\left[\left(1-s_{t+1}\right) \tilde{J}_{t, t+1}+s_{t+1} V_{t+1}\right]\right\} \\
&+c_{t}-\left[q_{t}(1-\kappa) \delta_{t} E_{t} \tilde{J}_{t, t+1}+\left(1-q_{t}\right) \delta_{t} E_{t} V_{t+1}\right] \\
&=\left(1-q_{t} \kappa\right)\left(p_{t}-w_{t}^{*}\right)+c_{t}+\delta_{t} E_{t}\left\{\left(1-q_{t} \kappa\right)\left[\left(1-s_{t+1}\right) \tilde{J}_{t, t+1}+s_{t+1} V_{t+1}\right]\right. \\
&\left.-\left[q_{t}(1-\kappa) \tilde{J}_{t, t+1}+\left(1-q_{t}\right) V_{t+1}\right]\right\} \\
&=\left(1-q_{t} \kappa\right)\left(p_{t}-w_{t}^{*}\right)+c_{t}+\delta_{t} E_{t}\left\{\left[\left(1-q_{t} \kappa\right)\left(1-s_{t+1}\right)-q_{t}(1-\kappa)\right] \tilde{J}_{t, t+1}\right. \\
&\left.+\left[\left(1-q_{t} \kappa\right) s_{t+1}-\left(1-q_{t}\right)\right] V_{t+1}\right\} \\
&=\left(1-q_{t} \kappa\right)\left(p_{t}-w_{t}^{*}\right)+c_{t}+\delta_{t} E_{t}\left\{\left[1-s_{t+1}-q_{t} \kappa+q_{t} \kappa s_{t+1}-q_{t}+q_{t} \kappa\right] \tilde{J}_{t, t+1}\right. \\
&\left.+\left[s_{t+1}-q_{t} \kappa s_{t+1}-1+q_{t}\right] V_{t+1}\right\} .
\end{aligned}
$$

This can be re-written as (A.27). 


\section{B.7 Derivation of equation (A.30)}

From (A.29) and (A.5),

$$
\begin{aligned}
& W_{t, t}-U_{t} \\
&=\left(1-f_{t} \kappa\right) W_{t, t}-\left[f_{t}(1-\kappa)\left(z_{t}+\delta_{t} E_{t} \tilde{W}_{t, t+1}\right)+\left(1-f_{t}\right)\left(z_{t}+\delta_{t} E_{t} U_{t+1}\right)\right] \\
&=\left(1-f_{t} \kappa\right)\left\{w_{t}^{*}+\delta_{t} E_{t}\left[\left(1-s_{t+1}\right) \tilde{W}_{t, t+1}+s_{t+1} U_{t+1}\right]\right\} \\
&-\left[f_{t}(1-\kappa) \delta_{t} E_{t} \tilde{W}_{t, t+1}+\left(1-f_{t}\right) \delta_{t} E_{t} U_{t+1}+f_{t}(1-\kappa) z_{t}+\left(1-f_{t}\right) z_{t}\right] \\
&=\left(1-f_{t} \kappa\right)\left(w_{t}^{*}-z_{t}\right)+\delta_{t} E_{t}\left\{\left(1-f_{t} \kappa\right)\left[\left(1-s_{t+1}\right) \tilde{W}_{t, t+1}+s_{t+1} U_{t+1}\right]\right. \\
&\left.-\left[f_{t}(1-\kappa) \tilde{W}_{t, t+1}+\left(1-f_{t}\right) U_{t+1}\right]\right\} \\
&=\left(1-f_{t} \kappa\right)\left(w_{t}^{*}-z_{t}\right)+\delta_{t} E_{t}\left\{\left[\left(1-f_{t} \kappa\right)\left(1-s_{t+1}\right)-f_{t}(1-\kappa)\right] \tilde{W}_{t, t+1}\right. \\
&\left.+\left[\left(1-f_{t} \kappa\right) s_{t+1}-\left(1-f_{t}\right)\right] U_{t+1}\right\} \\
&=\left(1-f_{t} \kappa\right)\left(w_{t}^{*}-z_{t}\right)+\delta_{t} E_{t}\left\{\left[1-s_{t+1}-f_{t} \kappa+f_{t} \kappa s_{t+1}-f_{t}+f_{t} \kappa\right] \tilde{W}_{t, t+1}\right. \\
&\left.+\left[s_{t+1}-f_{t} \kappa s_{t+1}-1+f_{t}\right] U_{t+1}\right\} .
\end{aligned}
$$

This can be re-written as (A.30).

\section{B.8 Derivation of equation (3)}

Use of (A.31) in (A.15) yields

$$
\begin{aligned}
& \left(1-f_{t} \kappa\right)\left(w_{t}^{*}-z_{t}\right)+\delta_{t} E_{t}\left\{\left(1-s_{t+1}-f_{t}\right.\right. \\
& \left.\left.\quad+\kappa f_{t} s_{t+1}\right)\left[\lambda\left(J_{t+1, t+1}-V_{t+1}\right)+\frac{\lambda}{1-\lambda} \gamma_{t+1}+\psi\left(J_{t+1, t+1}-J_{t, t+1}\right)\right]\right\} \\
& \quad=\lambda\left(J_{t, t}-V_{t}\right)+\frac{\lambda}{1-\lambda} \gamma_{t}
\end{aligned}
$$


or

$$
\begin{aligned}
& \left(1-f_{t} \kappa\right)\left(w_{t}^{*}-z_{t}\right) \\
& =\lambda\left(J_{t, t}-V_{t}\right) \\
& \quad-\delta_{t} E_{t}\left\{\left(1-s_{t+1}-f_{t}+\kappa f_{t} s_{t+1}\right)\left[\lambda\left(J_{t+1, t+1}-V_{t+1}\right)+\psi\left(J_{t+1, t+1}-J_{t, t+1}\right)\right]\right\} \\
& \quad+\frac{\lambda}{1-\lambda}\left\{\gamma_{t}-\delta_{t} E_{t}\left[\left(1-s_{t+1}-f_{t}+\kappa f_{t} s_{t+1}\right) \gamma_{t+1}\right]\right\} .
\end{aligned}
$$

From (A.28) (subtracting the second line below from both sides),

$$
\begin{aligned}
J_{t, t}- & V_{t} \\
& -\delta_{t} E_{t}\left\{\left(1-s_{t+1}-f_{t}+\kappa f_{t} s_{t+1}\right)\left[\left(J_{t+1, t+1}-V_{t+1}\right)+\frac{\psi}{\lambda}\left(J_{t+1, t+1}-J_{t, t+1}\right)\right]\right\} \\
=(1 & \left.-q_{t} \kappa\right)\left(p_{t}-w_{t}^{*}\right)+c_{t} \\
& +\delta_{t} E_{t}\left[\left(1-s_{t+1}-q_{t}+q_{t} \kappa s_{t+1}\right)\left(J_{t+1, t+1}-V_{t+1}-\psi\left(J_{t+1, t+1}-J_{t, t+1}\right)\right)\right] \\
& -\delta_{t} E_{t}\left\{\left(1-s_{t+1}-f_{t}+\kappa f_{t} s_{t+1}\right)\left[\left(J_{t+1, t+1}-V_{t+1}\right)+\frac{\psi}{\lambda}\left(J_{t+1, t+1}-J_{t, t+1}\right)\right]\right\}
\end{aligned}
$$

or

$$
\begin{aligned}
& J_{t, t}- V_{t} \\
&-\delta_{t} E_{t}\left\{\left(1-s_{t+1}-f_{t}+\kappa f_{t} s_{t+1}\right)\left[\left(J_{t+1, t+1}-V_{t+1}\right)+\frac{\psi}{\lambda}\left(J_{t+1, t+1}-J_{t, t+1}\right)\right]\right\} \\
&=\left(1-q_{t} \kappa\right)\left(p_{t}-w_{t}^{*}\right)+c_{t}+\delta_{t} E_{t}\left[\left[\left(1-s_{t+1}-q_{t}+q_{t} \kappa s_{t+1}\right)\right.\right. \\
& \\
&\left.\left.\quad-\left(1-s_{t+1}-f_{t}+\kappa f_{t} s_{t+1}\right)\right]\left(J_{t+1, t+1}-V_{t+1}\right)\right] \\
&-\psi \delta_{t} E_{t}\left[\left(1-s_{t+1}-q_{t}+q_{t} \kappa s_{t+1}\right)\left(J_{t+1, t+1}-J_{t, t+1}\right)\right. \\
&\left.+\left(1-s_{t+1}-f_{t}+\kappa f_{t} s_{t+1}\right) \frac{1}{\lambda}\left(J_{t+1, t+1}-J_{t, t+1}\right)\right]
\end{aligned}
$$


or

$$
\begin{aligned}
& J_{t, t}- V_{t} \\
&-\delta_{t} E_{t}\left\{\left(1-s_{t+1}-f_{t}+\kappa f_{t} s_{t+1}\right)\left[\left(J_{t+1, t+1}-V_{t+1}\right)+\frac{\psi}{\lambda}\left(J_{t+1, t+1}-J_{t, t+1}\right)\right]\right\} \\
&=\left(1-f_{t} \kappa\right)\left(p_{t}-w_{t}^{*}\right)+\kappa\left(f_{t}-q_{t}\right)\left(p_{t}-w_{t}^{*}\right)+c_{t} \frac{f_{t}}{q_{t}}-c_{t} \frac{f_{t}-q_{t}}{q_{t}} \\
& \quad+\left(f_{t}-q_{t}\right) \delta_{t} E_{t}\left[\left(1-\kappa s_{t+1}\right)\left(J_{t+1, t+1}-V_{t+1}\right)\right] \\
& \quad-\psi \delta_{t} E_{t}\left\{\left[\left(1+\frac{1}{\lambda}\right)\left(1-s_{t+1}\right)-\left(\frac{f_{t}}{\lambda}+q_{t}\right)\left(1-\kappa s_{t+1}\right)\right]\left(J_{t+1, t+1}-J_{t, t+1}\right)\right\}
\end{aligned}
$$

or

$$
\begin{aligned}
& J_{t, t}- V_{t} \\
&-\delta_{t} E_{t}\left\{\left(1-s_{t+1}-f_{t}+\kappa f_{t} s_{t+1}\right)\left[\left(J_{t+1, t+1}-V_{t+1}\right)+\frac{\psi}{\lambda}\left(J_{t+1, t+1}-J_{t, t+1}\right)\right]\right\} \\
&=\left(1-f_{t} \kappa\right)\left(p_{t}-w_{t}^{*}\right)+c_{t} \frac{f_{t}}{q_{t}}+\left(f_{t}-q_{t}\right)\left\{-\frac{c_{t}}{q_{t}}+\kappa\left(p_{t}-w_{t}^{*}\right)\right. \\
&\left.\quad+\delta_{t} E_{t}\left[\left(1-\kappa s_{t+1}\right)\left(J_{t+1, t+1}-V_{t+1}\right)\right]\right\} \\
& \quad-\psi \delta_{t} E_{t}\left\{\left[\left(1+\frac{1}{\lambda}\right)\left(1-s_{t+1}\right)-\left(\frac{f_{t}}{\lambda}+q_{t}\right)\left(1-\kappa s_{t+1}\right)\right]\left(J_{t+1, t+1}-J_{t, t+1}\right)\right\} .
\end{aligned}
$$

Hence (A.40) can be written

$$
\begin{aligned}
& \left(1-f_{t} \kappa\right)\left(w_{t}^{*}-z_{t}\right) \\
& =\lambda\left[\left(1-f_{t} \kappa\right)\left(p_{t}-w_{t}^{*}\right)+c_{t} \frac{f_{t}}{q_{t}}\right] \\
& \quad+\lambda\left(f_{t}-q_{t}\right)\left\{-\frac{c_{t}}{q_{t}}+\kappa\left(p_{t}-w_{t}^{*}\right)+\delta_{t} E_{t}\left[\left(1-\kappa s_{t+1}\right)\left(J_{t+1, t+1}-V_{t+1}\right)\right]\right\} \\
& \quad-\lambda \psi \delta_{t} E_{t}\left\{\left[\left(1+\frac{1}{\lambda}\right)\left(1-s_{t+1}\right)-\left(\frac{f_{t}}{\lambda}+q_{t}\right)\left(1-\kappa s_{t+1}\right)\right]\left(J_{t+1, t+1}-J_{t, t+1}\right)\right\} \\
& \quad+\frac{\lambda}{1-\lambda}\left\{\gamma_{t}-\delta_{t} E_{t}\left[\left(1-s_{t+1}-f_{t}+\kappa f_{t} s_{t+1}\right) \gamma_{t+1}\right]\right\} .
\end{aligned}
$$

With new vacancies created for which the wage is negotiated at every $t$, free entry (A.3) implies $V_{t}=V_{t+1}=0$. From (A.2) with $V_{t}=V_{t+1}=0$,

$$
\kappa J_{t, t}+(1-\kappa) \delta_{t} E_{t} \tilde{J}_{t, t+1}-\frac{c_{t}}{q_{t}}=0, \text { for all } t .
$$


Substitution for $J_{t, t}$ from (A.26) in this, with use of the free entry condition (A.3) so $V_{t+1}=0$, yields

$$
\kappa\left(p_{t}-w_{t}^{*}\right)+\kappa \delta_{t} E_{t}\left[\left(1-s_{t+1}\right) \tilde{J}_{t, t+1}\right]+(1-\kappa) \delta_{t} E_{t} \tilde{J}_{t, t+1}-\frac{c_{t}}{q_{t}}=0, \text { for all } t
$$

or

$$
\kappa\left(p_{t}-w_{t}^{*}\right)+\delta_{t} E_{t}\left[\left(1-\kappa s_{t+1}\right) \tilde{J}_{t+1, t+1}\right]-\frac{c_{t}}{q_{t}}=0, \text { for all } t .
$$

With the use of (A.22), this can be written

$$
\kappa\left(p_{t}-w_{t}^{*}\right)+\delta_{t} E_{t}\left\{\left(1-\kappa s_{t+1}\right)\left[J_{t+1, t+1}-\psi\left(J_{t+1, t+1}-J_{t, t+1}\right)\right]\right\}-\frac{c_{t}}{q_{t}}=0, \text { for all } t,
$$

or

$$
\kappa\left(p_{t}-w_{t}^{*}\right)+\delta_{t} E_{t}\left[\left(1-\kappa s_{t+1}\right) J_{t+1, t+1}\right]-\frac{c_{t}}{q_{t}}=\psi \delta_{t} E_{t}\left[\left(1-\kappa s_{t+1}\right)\left(J_{t+1, t+1}-J_{t, t+1}\right)\right]
$$

for all $t . \quad(\mathrm{A} .42)$

With the use of (A.42) and $V_{t+1}=0,(\mathrm{~A} .41)$ can be written

$$
\begin{aligned}
& \left(1-f_{t} \kappa\right)\left(w_{t}^{*}-z_{t}\right) \\
& =\lambda\left[\left(1-f_{t} \kappa\right)\left(p_{t}-w_{t}^{*}\right)+c_{t} \frac{f_{t}}{q_{t}}\right] \\
& \quad+\lambda\left(f_{t}-q_{t}\right) \psi \delta_{t} E_{t}\left[\left(1-\kappa s_{t+1}\right)\left(J_{t+1, t+1}-J_{t, t+1}\right)\right] \\
& \quad-\lambda \psi \delta_{t} E_{t}\left\{\left[\left(1+\frac{1}{\lambda}\right)\left(1-s_{t+1}\right)-\left(\frac{f_{t}}{\lambda}+q_{t}\right)\left(1-\kappa s_{t+1}\right)\right]\left(J_{t+1, t+1}-J_{t, t+1}\right)\right\} \\
& \quad+\frac{\lambda}{1-\lambda}\left\{\gamma_{t}-\delta_{t} E_{t}\left[\left(1-s_{t+1}-f_{t}+\kappa f_{t} s_{t+1}\right) \gamma_{t+1}\right]\right\}
\end{aligned}
$$

or

$$
\begin{aligned}
\left(1-f_{t} \kappa\right)\left(w_{t}^{*}-z_{t}\right) \\
=\lambda\left[\left(1-f_{t} \kappa\right)\left(p_{t}-w_{t}^{*}\right)+c_{t} \frac{f_{t}}{q_{t}}\right] \\
\quad+\lambda \psi \delta_{t} E_{t}\left\{\left[\left(f_{t}-q_{t}\right)\left(1-\kappa s_{t+1}\right)\right.\right. \\
\left.\left.\quad-\left(1+\frac{1}{\lambda}\right)\left(1-s_{t+1}\right)+\left(\frac{f_{t}}{\lambda}+q_{t}\right)\left(1-\kappa s_{t+1}\right)\right]\left(J_{t+1, t+1}-J_{t, t+1}\right)\right\} \\
\quad+\frac{\lambda}{1-\lambda}\left\{\gamma_{t}-\delta_{t} E_{t}\left[\left(1-s_{t+1}-f_{t}+\kappa f_{t} s_{t+1}\right) \gamma_{t+1}\right]\right\}
\end{aligned}
$$


Or

$$
\begin{aligned}
& \left(1-f_{t} \kappa\right)\left(w_{t}^{*}-z_{t}\right) \\
& =\lambda\left[\left(1-f_{t} \kappa\right)\left(p_{t}-w_{t}^{*}\right)+c_{t} \frac{f_{t}}{q_{t}}\right] \\
& \quad+\lambda \psi \delta_{t} E_{t}\left\{\left[f_{t}\left(1+\frac{1}{\lambda}\right)\left(1-\kappa s_{t+1}\right)-\left(1+\frac{1}{\lambda}\right)\left(1-s_{t+1}\right)\right]\left(J_{t+1, t+1}-J_{t, t+1}\right)\right\} \\
& \quad+\frac{\lambda}{1-\lambda}\left\{\gamma_{t}-\delta_{t} E_{t}\left[\left(1-s_{t+1}-f_{t}+\kappa f_{t} s_{t+1}\right) \gamma_{t+1}\right]\right\}
\end{aligned}
$$

or

$$
\begin{aligned}
& \left(1-f_{t} \kappa\right)\left(w_{t}^{*}-z_{t}\right) \\
& =\lambda\left[\left(1-f_{t} \kappa\right)\left(p_{t}-w_{t}^{*}\right)+c_{t} \frac{f_{t}}{q_{t}}\right] \\
& \quad+\psi(1+\lambda) \delta_{t} E_{t}\left\{\left[f_{t}\left(1-\kappa s_{t+1}\right)-\left(1-s_{t+1}\right)\right]\left(J_{t+1, t+1}-J_{t, t+1}\right)\right\} \\
& \quad+\frac{\lambda}{1-\lambda}\left\{\gamma_{t}-\delta_{t} E_{t}\left[\left(1-s_{t+1}-f_{t}+\kappa f_{t} s_{t+1}\right) \gamma_{t+1}\right]\right\} .
\end{aligned}
$$

With the definition $\delta_{t}^{\kappa}=\delta_{t-1}\left(1-s_{t}-f_{t-1}+\kappa s_{t} f_{t-1}\right)$, this can be written

$$
\begin{aligned}
& \left(1-f_{t} \kappa\right)\left(w_{t}^{*}-z_{t}\right) \\
& =\lambda\left[\left(1-f_{t} \kappa\right)\left(p_{t}-w_{t}^{*}\right)+c_{t} \frac{f_{t}}{q_{t}}\right]+\frac{\lambda}{1-\lambda}\left[\gamma_{t}-E_{t}\left(\delta_{t+1}^{\kappa} \gamma_{t+1}\right)\right] \\
& \quad-\psi(1+\lambda) E_{t}\left[\delta_{t+1}^{\kappa}\left(J_{t+1, t+1}-J_{t, t+1}\right)\right] .
\end{aligned}
$$

With the use of (A.25) averaged over all jobs, equation (A.43) can be written as (3).

\section{Appendix C “On the job” search}

In this appendix, we present a model of "on the job" search by workers and examine its implications for the persistence of aggregate wages. Following Hagedorn and Manovskii (2013), we consider match quality that is not the same for all matches and matched workers who can search on the job for better matches while still matched.

\section{C.1 Model}

Suppose, as assumed in Hagedorn and Manovskii (2013), productivity in a match, $p$, is idiosyncratic and drawn each time a worker and a job meet for potential matching from a distribution that is the same for all potential matches. Then the payoffs to being unemployed are the same 
for all those unemployed, and the payoffs to having an unfilled vacancy the same for all unfilled vacancies, and depend only on the distribution of productivities in potential matches.

Let $p_{t}^{k}$ denote the productivity at time $t$ of match $k$, and we will use similar notation for other variables, e.g., $w_{t}^{k}$. Without loss of generality, let $p_{t}^{k}=e_{t}^{k} \hat{p}_{t}$, where $e_{t}^{k}$ is an idiosyncratic component of productivity in match $k$, and $\hat{p}_{t}$ is aggregate productivity in potential matches. To proceed, we need to make assumptions about the distribution of the idiosyncratic component for potential matches and actual matches, which are not the same with "on the job" search. For potential new matches we assume that $e_{t}^{k}$ is independent and identically distributed (iid), and independent of $\hat{p}_{t}$, and we denote its distribution function by $\hat{\Phi}$. By the definition of $\hat{p}_{t}$, the mean of $\hat{\Phi}$ is one. For $e_{t}^{k}$ in continuing matches, we will consider the following two polar cases: (i) $e_{t}^{k}$ is redrawn every period from $\hat{\Phi}$ (no dependence); and (ii) $e_{t}^{k}$ is constant over the duration of match $k$, i.e. $e_{t}^{k}=e_{t-1}^{k}$ (perfect dependence). We assume that all potential matches are productive. Apart from that, no other restrictions on the support of the distributions $\hat{\Phi}$ and $\Phi_{t}$ are necessary, so we will omit the limits of integration except where integrating over a subset of the support.

For the model with "on the job" search we need to define the following additional variables:

\begin{tabular}{|l|l|}
\hline$\hat{f}_{t}$ & probability that an already matched worker finds a new match \\
$\zeta_{t}$ & probability worker with whom potential match is made is already matched \\
$\Phi_{t}(\cdot)$ & probability distribution of idiosyncratic productivity in actual matches \\
$\hat{\Phi}(\cdot)$ & probability distribution of idiosyncratic productivity in potential matches \\
$J_{t}^{k}$ & value to firm of match $k$ in period $t$ \\
$W_{t}^{k}$ & value to worker of match $k$ in period $t$ \\
$\hat{p}_{t}$ & average productivity across all potential matches \\
$p_{t}$ & average productivity in period $t$ across all actual matches \\
$\hat{J}_{t}$ & average value to firm of filling a vacancy with previously unmatched worker \\
$\tilde{J}_{t}$ & average value to firm of filling a vacancy with previously matched worker \\
$J_{t}$ & average value to firm of filling a vacancy,$J_{t}=\left(1-\zeta_{t}\right) \hat{J}_{t}+\zeta_{t} \tilde{J}_{t}$ \\
\hline
\end{tabular}

A worker already in match $k$ at the beginning of period $t$ changes job if finding a new match $k^{\prime}$ (which happens with probability $\hat{f}_{t}$ ) and the new match is of better quality than the existing one, $e_{t}^{k^{\prime}}>e_{t}^{k}$ (which happens with probability $1-\hat{\Phi}\left(e_{t}^{k}\right)$ ). The value of a filled job with productivity $p_{t}^{k}$ is

$$
J_{t}^{k}=p_{t}^{k}-w_{t}^{k}+\delta_{t} E_{t}^{k}\left\{\left[1-\hat{f}_{t+1}\left(1-\hat{\Phi}\left(e_{t+1}^{k}\right)\right)\right]\left(1-s_{t+1}\right) J_{t+1}^{k}\right\}, \text { for all } t, k,
$$

where $E_{t}^{k}$ denotes expectations conditional on aggregate and idiosyncratic information at $t$ and $\hat{f}_{t+1}\left[1-\hat{\Phi}\left(e_{t+1}^{k}\right)\right]$ is the probability of the worker finding a match $k^{\prime}$ with productivity $p_{t+1}^{k^{\prime}}>$ 
$p_{t+1}^{k}$. The free entry condition is

$$
V_{t}=0 \text {, for all } t
$$

Given this, the value of an unfilled vacancy is

$$
-c_{t}+q_{t}\left(1-\zeta_{t}\right) \hat{J}_{t}+q_{t} \zeta_{t} \tilde{J}_{t}=0, \text { for all } t .
$$

The reasoning is as follows. Making a vacancy available at $t$ costs $c_{t}$. With probability $q_{t}$, the vacancy meets with a worker. Conditional on meeting a worker, that worker is unemployed with probability $\left(1-\zeta_{t}\right)$, in which case a new match is made with the expected payoff to the vacancy creation conditional on this outcome given by

$$
\hat{J}_{t}=\int J_{t}^{k} d \hat{\Phi}^{k}
$$

where we use the shorthand notation $\hat{\Phi}^{k}=\Phi\left(e_{t}^{k}\right)$. With probability $\zeta_{t}$, the worker is already matched, in which case a new match is formed only if the (idiosyncratic) productivity draw for the new match exceeds that in the worker's current match $e_{t}^{k}$. So a new match is formed only if the productivity draw for the vacancy from the distribution $\hat{\Phi}$ exceeds $e_{t}^{k}$ and the expected payoff conditional on this outcome is

$$
\int_{e_{t}^{k}}^{\infty} J_{t}^{k^{\prime}} d \hat{\Phi}^{k^{\prime}}
$$

To get the expected payoff conditional on meeting a matched worker, this integral must itself be integrated over all the possible values of $e_{t}^{k}$, with the probability distribution of matches surviving from the previous period to get $\tilde{J}_{t}$, which is different depending on whether or not $e_{t-1}^{k}$ is redrawn for $t$. Note that (A.46) can also be written as

$$
0=-c_{t}+q_{t} J_{t}
$$

where $J_{t}$ is average value of filling a vacancy.

For the worker, the payoff in match $k$ is given by

$$
\begin{aligned}
W_{t}^{k} & =w_{t}^{k}+\delta_{t} E_{t}\left(s_{t+1} U_{t+1}\right)+\delta_{t} E_{t}^{k}\left\{\left(1-s_{t+1}\right)\right. \\
& \left.\times\left[\left(1-\hat{f}_{t+1}\left(1-\hat{\Phi}\left(e_{t+1}^{k}\right)\right)\right) W_{t+1}^{k}+\hat{f}_{t+1} \int_{e_{t+1}^{k}}^{\infty} W_{t+1}^{k^{\prime}} d \hat{\Phi}^{k^{\prime}}\right]\right\}, \text { for all } t, k .
\end{aligned}
$$

The payoff to starting period $t$ unemployed is

$$
U_{t}=f_{t} \hat{W}_{t}+\left(1-f_{t}\right)\left(z_{t}+\delta_{t} E_{t} U_{t+1}\right), \quad \text { for all } t,
$$


where

$$
\hat{W}_{t}=\int W_{t}^{k} d \hat{\Phi}^{k}
$$

Nash bargaining yields

$$
W_{t}^{k}-U_{t}=\lambda J_{t}^{k}, \text { for all } t, k
$$

\section{C.2 Wage equation}

We can rewrite (A.48) as

$$
\begin{aligned}
W_{t}^{k} & =w_{t}^{k}+\delta_{t} E_{t}\left(s_{t+1} U_{t+1}\right)+\delta_{t} E_{t}^{k}\left\{\left(1-s_{t+1}\right)\right. \\
& \times\left[\left(1-\hat{f}_{t+1}\left(1-\hat{\Phi}\left(e_{t+1}^{k}\right)\right)\right)\left(W_{t+1}^{k}-U_{t+1}\right)\right. \\
& \left.\left.+\hat{f}_{t+1} \int_{e_{t+1}^{k}}^{\infty}\left(W_{t+1}^{k^{\prime}}-U_{t+1}\right) d \hat{\Phi}^{k^{\prime}}\right]\right\}+\delta_{t} E_{t}^{k}\left[\left(1-s_{t+1}\right) U_{t+1}\right]
\end{aligned}
$$

or

$$
\begin{aligned}
W_{t}^{k} & =w_{t}^{k}+\delta_{t} E_{t}\left(U_{t+1}\right)+\delta_{t} E_{t}^{k}\left\{\left(1-s_{t+1}\right)\right. \\
& \times\left[\left(1-\hat{f}_{t+1}\left(1-\hat{\Phi}\left(e_{t+1}^{k}\right)\right)\right)\left(W_{t+1}^{k}-U_{t+1}\right)\right. \\
& \left.\left.+\hat{f}_{t+1} \int_{e_{t+1}^{k}}^{\infty}\left(W_{t+1}^{k^{\prime}}-U_{t+1}\right) d \hat{\Phi}^{k^{\prime}}\right]\right\}
\end{aligned}
$$

Substituting for $W_{t}^{k}-U_{t}=\lambda J_{t}^{k}$ from the Nash bargain into (A.51) yields

$$
\begin{aligned}
W_{t}^{k} & =w_{t}^{k}+\delta_{t} E_{t}\left(U_{t+1}\right)+\lambda \delta_{t} E_{t}^{k}\left\{\left(1-s_{t+1}\right)\right. \\
& \left.\times\left[\left(1-\hat{f}_{t+1}\left(1-\hat{\Phi}\left(e_{t+1}^{k}\right)\right)\right) J_{t+1}^{k}+\hat{f}_{t+1} \int_{e_{t+1}^{k}}^{\infty} J_{t+1}^{k^{\prime}} d \hat{\Phi}^{k^{\prime}}\right]\right\} .
\end{aligned}
$$

Taking expectations over $k$ in (A.44) with respect to the distribution $\Phi$ in all matches, we have

$$
J_{t}=p_{t}-w_{t}+A_{t}
$$

where

$$
A_{t}=\delta_{t} \int E_{t}^{k}\left\{\left(1-s_{t+1}\right)\left(1-\hat{f}_{t+1}\left[\left(1-\hat{\Phi}\left(e_{t_{-}}^{k}\right)\right)\right]\right) J_{t+1}^{k}\right\} d \Phi_{t}^{k} .
$$


Taking expectations over $k$ in (A.44) with respect to the distribution $\hat{\Phi}$ in potential new matches, we have

$$
\hat{J}_{t}=\hat{p}_{t}-\hat{w}_{t}+\hat{A}_{t}, \quad \text { for all } t,
$$

where

$$
\hat{A}_{t}=\delta_{t} \int E_{t}^{k}\left\{\left(1-s_{t+1}\right)\left(1-\hat{f}_{t+1}\left[\left(1-\hat{\Phi}\left(e_{t+1}^{k}\right)\right)\right]\right) J_{t+1}^{k}\right\} d \hat{\Phi}^{k} .
$$

Averaging (A.52) over $k$ using $\Phi_{t}$ yields

$$
W_{t}=w_{t}+\delta_{t} E_{t}\left(U_{t+1}\right)+\lambda A_{t}+\lambda B_{t}
$$

where

$$
B_{t}=\delta_{t} \int E_{t}^{k}\left[\left(1-s_{t+1}\right) \hat{f}_{t+1}\left(\int_{e_{t+1}^{k}}^{\infty} J_{t+1}^{k^{\prime}} d \hat{\Phi}^{k^{\prime}}\right)\right] d \Phi_{t}^{k} .
$$

Similarly, averaging (A.52) over $k$ using $\hat{\Phi}_{t}$ yields

$$
\hat{W}_{t}=\hat{w}_{t}+\delta_{t} E_{t}\left(U_{t+1}\right)+\lambda \hat{A}_{t}+\lambda \hat{B}_{t},
$$

where

$$
\hat{B}_{t}=\delta_{t} \int E_{t}^{k}\left[\left(1-s_{t+1}\right) \hat{f}_{t+1}\left(\int_{e_{t+1}^{k}}^{\infty} J_{t+1}^{k^{\prime}} d \hat{\Phi}^{k^{\prime}}\right)\right] d \hat{\Phi}^{k} .
$$

Equations (A.49) and (A.59) imply

$$
\begin{aligned}
U_{t}-\delta_{t} E_{t}\left(U_{t+1}\right) & =\left(1-f_{t}\right) z_{t}+f_{t}\left(\hat{W}_{t}-\delta_{t} E_{t} U_{t+1}\right) \\
& =\left(1-f_{t}\right) z_{t}+f_{t} \hat{w}_{t}+\lambda f_{t}\left(\hat{A}_{t}+\hat{B}_{t}\right) .
\end{aligned}
$$

Averaging (A.50) over $k$ using $\hat{\Phi}_{t}$ yields

$$
\hat{W}_{t}=\lambda \hat{J}_{t}+U_{t}
$$

Using this to substitute for $\hat{W}_{t}$ in (A.59), using (A.60) and rearranging yields

$$
\lambda \hat{J}_{t}=\left(1-f_{t}\right)\left(\hat{w}_{t}-z_{t}\right)+\lambda\left(1-f_{t}\right)\left(\hat{A}_{t}+\hat{B}_{t}\right) .
$$

Substituting for $\hat{A}_{t}$ using (A.55) yields

$$
\lambda \hat{J}_{t}=\left(1-f_{t}\right)\left(\hat{w}_{t}-z_{t}\right)+\lambda\left(1-f_{t}\right)\left(\hat{J}_{t}+\hat{w}_{t}-\hat{p}_{t}\right)+\lambda\left(1-f_{t}\right) \hat{B}_{t},
$$

or

$$
\lambda f_{t} \hat{J}_{t}=\left(1-f_{t}\right)\left((1+\lambda) \hat{w}_{t}-\lambda \hat{p}_{t}-z_{t}\right)+\lambda\left(1-f_{t}\right) \hat{B}_{t}
$$


Rearranging yields

$$
(1+\lambda) \hat{w}_{t}-\lambda \hat{p}_{t}=z_{t}+\lambda\left(\frac{f_{t}}{1-f_{t}} \hat{J}_{t}-\hat{B}_{t}\right) .
$$

Averaging (A.50) over $k$ using $\Phi_{t}$ yields

$$
W_{t}=\lambda J_{t}+U_{t}
$$

Using this to substitute for $W_{t}$ in (A.57), using (A.60) and rearranging yields

$$
\lambda J_{t}=w_{t}-\left(1-f_{t}\right) z_{t}-f_{t} \hat{w}_{t}+\lambda\left(A_{t}+B_{t}\right)-\lambda f_{t}\left(\hat{A}_{t}+\hat{B}_{t}\right) .
$$

Substituting for $J_{t}$ using (A.53) and $\hat{A}_{t}$ using (A.55) yields

$$
\lambda\left(p_{t}-w_{t}\right)=w_{t}-\left(1-f_{t}\right) z_{t}-f_{t} \hat{w}_{t}+\lambda B_{t}-\lambda f_{t}\left(\hat{J}_{t}+\hat{w}_{t}-\hat{p}_{t}+\hat{B}_{t}\right),
$$

or

$$
\lambda p_{t}+f_{t} \hat{w}_{t}+\lambda f_{t}\left(\hat{w}_{t}-\hat{p}_{t}\right)=(1+\lambda) w_{t}-\left(1-f_{t}\right) z_{t}+\lambda B_{t}-\lambda f_{t}\left(\hat{J}_{t}+\hat{B}_{t}\right),
$$

or

$$
\lambda p_{t}+f_{t}\left[(1+\lambda) \hat{w}_{t}-\lambda \hat{p}_{t}\right]=(1+\lambda) w_{t}-\left(1-f_{t}\right) z_{t}+\lambda B_{t}-\lambda f_{t}\left(\hat{J}_{t}+\hat{B}_{t}\right)
$$

Using (A.61) in this yields

$$
\lambda p_{t}+f_{t} z_{t}+\lambda f_{t}\left(\frac{f_{t}}{1-f_{t}} \hat{J}_{t}-\hat{B}_{t}\right)=(1+\lambda) w_{t}-\left(1-f_{t}\right) z_{t}+\lambda B_{t}-\lambda f_{t}\left(\hat{J}_{t}+\hat{B}_{t}\right),
$$

or

$$
\lambda p_{t}+f_{t} z_{t}+\lambda f_{t} \frac{f_{t}}{1-f_{t}} \hat{J}_{t}=(1+\lambda) w_{t}-\left(1-f_{t}\right) z_{t}+\lambda B_{t}-\lambda f_{t} \hat{J}_{t},
$$

or

$$
\lambda p_{t}=(1+\lambda) w_{t}-z_{t}+\lambda B_{t}-\lambda f_{t}\left(\frac{f_{t}}{1-f_{t}}+1\right) \hat{J}_{t},
$$

or

$$
w_{t}=\frac{1}{1+\lambda} z_{t}+\frac{\lambda}{1+\lambda}\left(p_{t}+\frac{f_{t}}{1-f_{t}} \hat{J}_{t}\right)-\frac{\lambda}{1+\lambda} B_{t} .
$$

The free entry condition (A.46) implies

$$
\hat{J}_{t}=\frac{c_{t} / q_{t}-\zeta_{t} \tilde{J}_{t}}{1-\zeta_{t}}
$$

Using this to substitute for $\hat{J}_{t}$ in (A.62) yields

$$
w_{t}=\frac{1}{1+\lambda} z_{t}+\frac{\lambda}{1+\lambda}\left(p_{t}+\frac{f_{t}}{1-f_{t}} \frac{c_{t} / q_{t}-\zeta_{t} \tilde{J}_{t}}{1-\zeta_{t}}\right)-\frac{\lambda}{1+\lambda} B_{t},
$$


which is equation (A.20) in Section A.3.1. With no "on the job" search, $\zeta_{t}=\hat{f}_{t}=B_{t}=0$, so this reduces exactly to the wage equation (1) in the main paper.

Our concern here is how changes in the distribution $\Phi_{t}$ over time affect the persistence of wages in (A.63). The term $B_{t}$ does not depend on the past productivity distribution $\Phi_{t-1}$, so we need to consider only $\tilde{J}_{t}$. Consider the two polar cases that we mentioned at the beginning. Under the assumption that $e_{t}^{k}$ in continuing matches is redrawn from the distribution of potential matches $\hat{\Phi}$, we have

$$
\tilde{J}_{t}=\int\left(\int_{e_{t}^{k}}^{\infty} J_{t}^{k^{\prime}} d \hat{\Phi}^{k^{\prime}}\right) d \hat{\Phi}^{k}
$$

This clearly does not depend on $\Phi_{t-1}$, so does not introduce any additional persistence to wages.

Our alternative assumption is that idiosyncratic productivity is constant in continuing matches, so $e_{t}^{k}=e_{t-1}^{k}$. Hence

$$
\tilde{J}_{t}=\int\left(\int_{e_{t-1}^{k}}^{\infty} J_{t}^{k^{\prime}} d \hat{\Phi}^{k^{\prime}}\right) d \Phi_{t-1}\left(e_{t-1}^{k}\right)=\int\left(\int_{e_{t-1}^{k}}^{\infty} J_{t}^{k^{\prime}} d \hat{\Phi}^{k^{\prime}}\right) d \Phi_{t-1}^{k}
$$

In this case, $w_{t}$ depends on the past productivity distribution $\Phi_{t-1}$. Moreover, since $\tilde{J}_{t}$ appears with a negative sign, the effect of a positive productivity shock in period $t-1$ would be to reduce wages in period $t$, other things equal.

\begin{tabular}{|c|c|c|c|c|}
\hline Series & Description & Source & Series ID & Sample \\
\hline Labor share & nfb, sa, level & BLS & PRS85006173 & 1948q1-2011q3 \\
\hline Output per person & $\mathrm{nfb}, \mathrm{sa}$, index & BLS & PRS85006163 & $1948 \mathrm{q} 1-2011 \mathrm{q} 4$ \\
\hline Unemployment & total, sa, end of quarter & BLS & LNS13000000 & $1948 q 1-2011 q 4$ \\
\hline Unemployment & total, nsa, end of quarter & BLS & LNU03000000 & $1948 q 1-2011 q 4$ \\
\hline Unemployment rate & sa, quarterly average & BLS & LNS14000000Q & $1948 q 1-2011 q 4$ \\
\hline Unempl. $<5$ weeks & total, sa, monthly & BLS & LNS13008396 & $1948 \mathrm{~m} 1-2011 \mathrm{~m} 12$ \\
\hline Unempl. $<5$ weeks & total, nsa, monthly & BLS & LNU03008396 & $1948 \mathrm{~m} 1-2011 \mathrm{~m} 12$ \\
\hline Unempl. 5 - 14 weeks & total, sa, monthly & BLS & LNS13008396 & 1948m1-2011m12 \\
\hline Unempl. 5 - 14 weeks & total, nsa, monthly & BLS & LNU03008756 & 1948m1-2011m12 \\
\hline Unempl. $<14$ weeks & total, last month of quarter & derived & - & $1948 \mathrm{q} 1-2011 \mathrm{q} 4$ \\
\hline Employment & nf, total, sa, end of quarter & BLS & CES0000000001 & $1948 q 1-2011 q 4$ \\
\hline Employment & nf, total, nsa, end of quarter & BLS & CEU0000000001 & $1948 q 1-2011 q 4$ \\
\hline Help Wanted Index (HWI) & index, sa & MEI & & 1951q1-2008q1 \\
\hline Job openings rate & $\frac{\text { openings }}{\text { openings }+ \text { employment }}$ & Barnichon (2010) & - & 1951q1-2011q3 \\
\hline Job openings & $\mathrm{nf}$, total, sa, total over quarter & BLS/JOLTS & JTS00000000JOL & $2001 q 1-2011 q 4$ \\
\hline Separations & $\mathrm{nf}$, total, sa, total over quarter & BLS/JOLTS & JTS00000000TSL & $2001 q 1-2011 q 4$ \\
\hline $3 \mathrm{mTbill}$ & sec. market rate, quart. av. & FRED & TB3MS_20120305 & $1948 q 1-2011 q 4$ \\
\hline Implicit price deflator & $\mathrm{nfb}$, index & BLS & PRS85006143 & $1948 q 1-2011 q 4$ \\
\hline
\end{tabular}

\section{Appendix D Data}

Table 8: Data description and sources. 
Abbreviations: $\mathrm{nfb}$ is nonfarm business sector, $\mathrm{nf}$ is nonfarm sector, sa is seasonally adjusted, nsa is non-seasonally adjusted, end of quarter is last month of quarter.

Sources: BLS is Bureau of Labor Statistics, JOLTS is Job Openings and Labor Turnover Survey, MEI is OECD Main Economic Indicators, FRED is St. Louis Fed's Economic Database.

Table 8 specifies the raw data we use, with sources. Figure 1 uses the original data of Hagedorn and Manovskii (2008), downloaded from the $A E R$ website. This data contains series for the labour share, output per person, the unemployment rate and HWI from 1951q1 to 2004q4. All other empirical results in the paper use the most recent revisions of these series. A comparison of the series used by Hagedorn and Manovskii (2008) with the most recent revisions is in Table 9. For the labour share and productivity series, the revisions are minor. The unemployment and HWI series are identical.

Vacancies are measured using the approach described in Shimer (2005, p. 29), specifically removing variations at very low frequency (in logs), computed using the HP filter with smoothing parameter $10^{5}$. Barnichon (2010) provides a different vacancy series, available from his website. This is derived by merging newspaper advertising data (which was discontinued after 2008q1) with online advertising (available since 1995) to create a composite HWI index. Barnichon (2010) reports a vacancy rate series $v^{r}$ that conforms to the JOLTS definition, that is, $v^{r}=\frac{V}{V+J}$, where $V$ is total vacancies and $J$ is employment. Using our data on employment, we obtain a measure of

total vacancies as $V=\frac{v^{r}}{1-v^{r}} J$. (We compute this at the monthly frequency and then aggregate to quarterly).

Vacancy data are used primarily for a measure of the probability of filling a vacancy, $q_{t}$. Table 10 compares series for this probability using the different vacancy series. Our baseline measure (based on filtered HWI), constructed as in Shimer (2005), is very similar to the measure based on JOLTS data (correlation 0.88). It is also very similar to the one based on the vacancy data constructed by Barnichon (2010) (correlation 0.97). The measure that uses the raw (unfiltered) HWI data is very different from the others.

Summary statistics for the series that appear in the model of equation (3) are in Table 11.

\section{Appendix E Additional empirical results}

This appendix gives details of various robustness checks.

Table 12 gives estimates corresponding to column 4 of Table 4 for different truncation lengths of the infinite sum on the right-hand side of equation (3). The point estimates are identical to 3 decimal places for truncations of 8 or more quarters.

Table 13 gives estimates corresponding to Table 4 with wages and productivity separately de- 


\begin{tabular}{l|ccc}
\hline \hline Series & st. dev. & first autocorrelation & correlation \\
\hline Labor share, ours & 0.020 & 0.899 & 0.989 \\
Labor share, HM & 0.020 & 0.907 & - \\
\hline $\log$ (prod)-HP trend, ours & 0.0133 & 0.758 & 0.990 \\
$\log$ (prod)-HP trend, HM & 0.0132 & 0.765 & - \\
\hline Unemployment rate, ours & 0.015 & 0.966 & 1 \\
Unemployment rate, HM & 0.015 & 0.966 & - \\
\hline HWI (unfiltered), ours & 0.373 & 0.978 & 1 \\
HWI (unfiltered), HM & 0.373 & 0.978 & - \\
\hline \hline
\end{tabular}

Table 9: Comparison of Hagedorn and Manovskii (2008) data series (HM) with the most recent revisions (ours). HP trend is computed with smoothing parameter 1600.

Correlations over JOLTS sample 2001q1-2008q1

\begin{tabular}{l|ccc}
\hline \hline Vacancy series & Unfiltered HWI & Barnichon (2010) & JOLTS \\
\hline Filtered HWI & 0.161 & 0.965 & 0.876 \\
Unfiltered HWI & 1 & 0.104 & 0.103 \\
\hline Barnichon (2010) & & 1 & 0.956 \\
\hline JOLTS & \multicolumn{3}{c}{1} \\
\hline \hline
\end{tabular}

Summary statistics

\begin{tabular}{l|cccc}
\hline \hline & \multicolumn{3}{|c}{ JOLTS sample 2001q1-2008q1 } & \multicolumn{2}{c}{ full sample 1951q1-2008q1 } \\
\hline \hline Vacancy series & st. dev. & first autocorrelation & st. dev. & first autocorrelation \\
\hline Filtered HWI & 0.040 & 0.776 & 0.067 & 0.944 \\
Unfiltered HWI & 0.064 & 0.691 & 0.097 & 0.943 \\
\hline Barnichon (2010) & 0.042 & 0.789 & 0.073 & 0.945 \\
\hline JOLTS & 0.044 & 0.834 & - & - \\
\hline \hline
\end{tabular}

Table 10: Series for probability of filling a vacancy with different vacancy series.

\begin{tabular}{l|c|c}
\hline \hline Series & st. dev. & first autocorrelation \\
\hline$w_{t}$ & 0.017 & 0.940 \\
\hline$p_{t}$ & 0.013 & 0.762 \\
\hline$f_{t}$ & 0.066 & 0.941 \\
\hline$q_{t}$ & 0.032 & 0.741 \\
\hline$s_{t}$ & 0.015 & 0.914 \\
\hline$\delta_{t}$ & 0.006 & 0.681 \\
\hline$\pi_{t}$ & 0.007 & 0.818 \\
\hline \hline
\end{tabular}

Table 11: Summary statistics for the variables used in the econometric model. $w_{t}$ and $p_{t}$ are detrended using HP filter-based productivity trend. 


\begin{tabular}{c|cccccc}
\hline \hline Truncation length (quarters): & 28 & 24 & 20 & 16 & 12 & 8 \\
\hline$\psi$ & 0.631 & 0.631 & 0.631 & 0.631 & 0.631 & 0.631 \\
$\mu$ & 0.000 & 0.000 & 0.000 & 0.000 & 0.000 & 0.000 \\
$z$ & 1.000 & 1.000 & 1.000 & 1.000 & 1.000 & 1.000 \\
$c^{K}$ & 0.000 & 0.000 & 0.000 & 0.000 & 0.000 & 0.000 \\
$c^{W}$ & 0.083 & 0.083 & 0.083 & 0.083 & 0.083 & 0.083 \\
$\xi$ & 0.000 & 0.000 & 0.000 & 0.000 & 0.000 & 0.000 \\
$\kappa$ & 1.000 & 1.000 & 1.000 & 1.000 & 1.000 & 1.000 \\
$H^{K}$ & 0.011 & 0.011 & 0.011 & 0.011 & 0.011 & 0.011 \\
$H^{W}$ & 1.145 & 1.145 & 1.145 & 1.145 & 1.145 & 1.145 \\
$\gamma$ & -1.376 & -1.376 & -1.376 & -1.376 & -1.376 & -1.376 \\
$\lambda$ & 0.131 & 0.131 & 0.131 & 0.131 & 0.131 & 0.131 \\
\hline GMM objective & 8.923 & 8.923 & 8.923 & 8.923 & 8.920 & 8.909 \\
\hline \hline
\end{tabular}

Table 12: Estimates of eq. (3) with truncation of the infinite sum at various quarters.

trended (using separate HP filters). The fit is slightly worse than with the baseline specification in Table 4. The point estimates of the parameters are similar, with somewhat higher $\beta$ and lower $\lambda$ (though still well within the confidence intervals given in Table 5 for the baseline specification), but with point estimates of zero for both the vacancy posting cost parameters. The point estimates of $\psi$ remain significantly greater than zero, so our main conclusions are unaffected.

Table 14 gives estimates corresponding to Table 4 using the following instrument set: a constant, four lags of $w_{t}$ and three lags of $p_{t}, f_{t}, q_{t}$, and $s_{t}$. The conclusions to be drawn remain unchanged.

Table 15 gives estimates corresponding to Table 4 with non-seasonally adjusted data for employment and unemployment. The fit is slightly worse than in the baseline specification in Table 4 but the conclusions we draw remain unchanged.

Table 16 gives estimates corresponding to Table 4 with vacancy data as computed by Barnichon (2010) and the sample extended by 3 years to 2007q4. These give somewhat higher point estimates for $\beta$ and $\lambda$ than the baseline specification in Table 4 (though still well within the confidence intervals given in Table 5 for the baseline specification). But the estimates of the wage rigidity parameter $\psi$ are not very different, so our main conclusions remain unchanged. 


\begin{tabular}{c|cccc}
\hline \hline Parameter & 1 & 2 & 3 & 4 \\
\hline$\psi$ & 0.682 & 0.682 & 0.682 & 0.516 \\
$\mu$ & $(0.024)$ & $(0.054)$ & $(0.064)$ & $(0.078)$ \\
$\beta$ & 0.040 & 0.040 & 0.040 & 0.000 \\
& $(0.179)$ & $(0.190)$ & $(0.292)$ & $(0.271)$ \\
$z$ & 0.280 & 0.280 & 0.280 & - \\
$c^{K}$ & $(1.450)$ & $(1.476)$ & $(5.208)$ & $(-)$ \\
$c^{W}$ & 0.930 & 0.930 & 0.930 & 1.000 \\
& $(0.143)$ & $(0.147)$ & $(0.528)$ & $(0.034)$ \\
$\xi$ & 0.000 & 0.000 & 0.000 & 0.000 \\
$\kappa$ & $(8.265)$ & $(8.437)$ & $(18.856)$ & $(23.25)$ \\
$\kappa$ & 0.000 & 0.000 & 0.000 & 0.000 \\
$H^{K}$ & $(8.267)$ & $(8.440)$ & $(18.858)$ & $(23.27)$ \\
& 0.097 & 0.097 & 0.097 & 0.164 \\
& $\left(3 \times 10^{13}\right)$ & $\left(3 \times 10^{13}\right)$ & $\left(3 \times 10^{13}\right)$ & $(3518)$ \\
& - & 0.000 & 0.000 & 1.000 \\
$\gamma$ & $(-)$ & $(0.588)$ & $(0.838)$ & $(0.467)$ \\
& - & - & 0.000 & 1.470 \\
$\lambda$ & $(-)$ & $(-)$ & $(64.660)$ & $(1217)$ \\
& - & - & 0.000 & 0.337 \\
& $(-)$ & $(-)$ & $(64.812)$ & $(1333)$ \\
GMM objective & - & - & - & -1.877 \\
Hansen test $p$ value & 0.358 & 0.358 & 0.358 & 0.490 \\
\hline \hline & $(-)$ & $(-)$ & $(-)$ & $(150.3)$ \\
\hline \hline
\end{tabular}

Table 13: Estimates of eq. (3) as in Table 4 with wages detrended by an HP filter with smoothing parameter 1600, instead of by the productivity trend. 


\begin{tabular}{c|cccc}
\hline \hline Parameter & 1 & 2 & 3 & 4 \\
\hline$\psi$ & 0.746 & 0.746 & 0.746 & 0.632 \\
$\mu$ & $(0.028)$ & $(0.054)$ & $(0.062)$ & $(0.079)$ \\
$\beta$ & 0.256 & 0.256 & 0.256 & 0.060 \\
$z$ & $(0.188)$ & $(0.222)$ & $(0.259)$ & $(0.542)$ \\
$c^{K}$ & 0.020 & 0.020 & 0.020 & - \\
$c^{W}$ & $(3.493)$ & $(4.041)$ & $(11.940)$ & $(-)$ \\
$\xi$ & 0.950 & 0.950 & 0.950 & 1.000 \\
$\kappa$ & $(0.180)$ & $(0.210)$ & $(0.621)$ & $(0.104)$ \\
$\kappa$ & 0.330 & 0.330 & 0.330 & 0.704 \\
$H^{K}$ & $(5375.722)$ & $(7596.439)$ & $(9385.721)$ & $(3308.491)$ \\
& 0.504 & 0.504 & 0.504 & 0.482 \\
$H^{W}$ & $(5463.599)$ & $(7717.699)$ & $(9784.890)$ & $(3642.685)$ \\
& 0.162 & 0.162 & 0.162 & 0.800 \\
$\gamma$ & $(9281.905)$ & $(13099.239)$ & $(16085.326)$ & $(1074.968)$ \\
& - & 0.000 & 0.000 & 0.931 \\
$\lambda$ & $(-)$ & $(0.544)$ & $(0.660)$ & $(0.450)$ \\
& - & - & 0.000 & 0.629 \\
& $(-)$ & $(-)$ & $(1431.706)$ & $(31165.073)$ \\
& - & - & 0.000 & 6.284 \\
Hansen test $p$ value & $(-)$ & $(-)$ & $(1435.087)$ & $(32967.394)$ \\
Hansen test proj. $p$ value & 0.829 & 0.829 & 0.829 & 0.953 \\
\hline \hline
\end{tabular}

Table 14: Estimates of eq. (3) as in Table 4 with the instrument set consisting of a constant, four lags of $w_{t}$ and three lags of $p_{t}, q_{t}, f_{t}$ and $s_{t}$. 


\begin{tabular}{c|cccc}
\hline \hline Parameter & 1 & 2 & 3 & 4 \\
\hline$\psi$ & 0.736 & 0.736 & 0.736 & 0.616 \\
$\mu$ & $(0.050)$ & $(0.054)$ & $(0.072)$ & $(0.078)$ \\
$\beta$ & 0.301 & 0.301 & 0.301 & 0.242 \\
& $(0.272)$ & $(0.283)$ & $(0.273)$ & $(0.304)$ \\
$z$ & 0.013 & 0.013 & 0.013 & - \\
$c^{K}$ & $(3.022)$ & $(3.071)$ & $(4.625)$ & $(-)$ \\
$c^{W}$ & 0.951 & 0.951 & 0.951 & 0.952 \\
& $(0.162)$ & $(0.166)$ & $(0.242)$ & $(0.113)$ \\
$\xi$ & 0.294 & 0.294 & 0.294 & 0.000 \\
$\kappa$ & $(10293.212)$ & $(10302.540)$ & $(11957.181)$ & $(15722.291)$ \\
$H^{K}$ & 1.334 & 1.334 & 1.334 & 1.159 \\
& $(10626.352)$ & $(10640.468)$ & $(12461.001)$ & $(16188.884)$ \\
$H^{W}$ & 0.000 & 0.000 & 0.000 & 0.033 \\
& $(7971.002)$ & $(7980.958)$ & $(9111.905)$ & $(12910.579)$ \\
$\gamma$ & - & 0.000 & 0.000 & 1.000 \\
& $(-)$ & $(0.508)$ & $(0.626)$ & $(0.319)$ \\
$\lambda$ & - & - & 0.000 & 0.002 \\
& $(-)$ & $(-)$ & $(797.681)$ & $(1386.153)$ \\
& - & - & 0.000 & 0.127 \\
& $(-)$ & $(-)$ & $(797.131)$ & $(1403.494)$ \\
Hansen test proj. $p$ value & - & - & - & -0.055 \\
Han objective & 17.824 & 17.824 & 17.824 & 15.150 \\
\hline \hline & 0.086 & 0.086 & 0.086 & 0.056 \\
& $(-)$ & $(-)$ & $(-)$ & $(33.678)$ \\
\hline
\end{tabular}

Table 15: Estimates of eq. (3) as in Table 4 with non-seasonally adjusted data for employment and unemployment. 


\begin{tabular}{c|cccc}
\hline \hline Parameter & 1 & 2 & 3 & 4 \\
\hline$\psi$ & 0.674 & 0.670 & 0.670 & 0.670 \\
$\mu$ & $(0.034)$ & $(0.056)$ & $(0.068)$ & $(0.071)$ \\
$\beta$ & 0.000 & 0.000 & 0.000 & 0.000 \\
& $(0.366)$ & $(0.370)$ & $(0.388)$ & $(0.453)$ \\
$z$ & 0.386 & 0.385 & 0.385 & - \\
$c^{K}$ & $(1.937)$ & $(2.040)$ & $(17.793)$ & $(-)$ \\
$c^{W}$ & 0.909 & 0.908 & 0.908 & 0.911 \\
$\xi$ & $(0.283)$ & $(0.301)$ & $(2.810)$ & $(2.622)$ \\
& 0.000 & 0.000 & 0.000 & 0.000 \\
$\kappa$ & $(221.351)$ & $(250.214)$ & $(749.895)$ & $(788.170)$ \\
$H^{K}$ & 0.028 & 0.030 & 0.030 & 0.031 \\
& $(221.437)$ & $(250.321)$ & $(751.319)$ & $(789.446)$ \\
$H^{W}$ & 0.248 & 0.269 & 0.269 & 0.356 \\
& $(6147.263)$ & $(6341.802)$ & $(18459.787)$ & $(16322.833)$ \\
$\gamma$ & - & 0.000 & 0.000 & 0.000 \\
& $(-)$ & $(0.468)$ & $(0.534)$ & $(0.762)$ \\
$\lambda$ & - & - & 0.000 & 0.000 \\
& $(-)$ & $(-)$ & $(140.474)$ & $(155.331)$ \\
& - & - & 0.000 & 0.000 \\
Hansen test $p$ value & $(-)$ & $(-)$ & $(141.168)$ & $(155.220)$ \\
Hansen test proj. $p$ value & 0.143 & 0.144 & 0.144 & 0.103 \\
\hline \hline & - & - & - & -0.004 \\
\hline & $(-)$ & $(-)$ & $(-)$ & $(1.244)$ \\
\hline
\end{tabular}

Table 16: Estimates of eq. (3) as in Table 4 with vacancy data computed by Barnichon (2010) and the sample extended by 3 years to $2007 q 4$. 